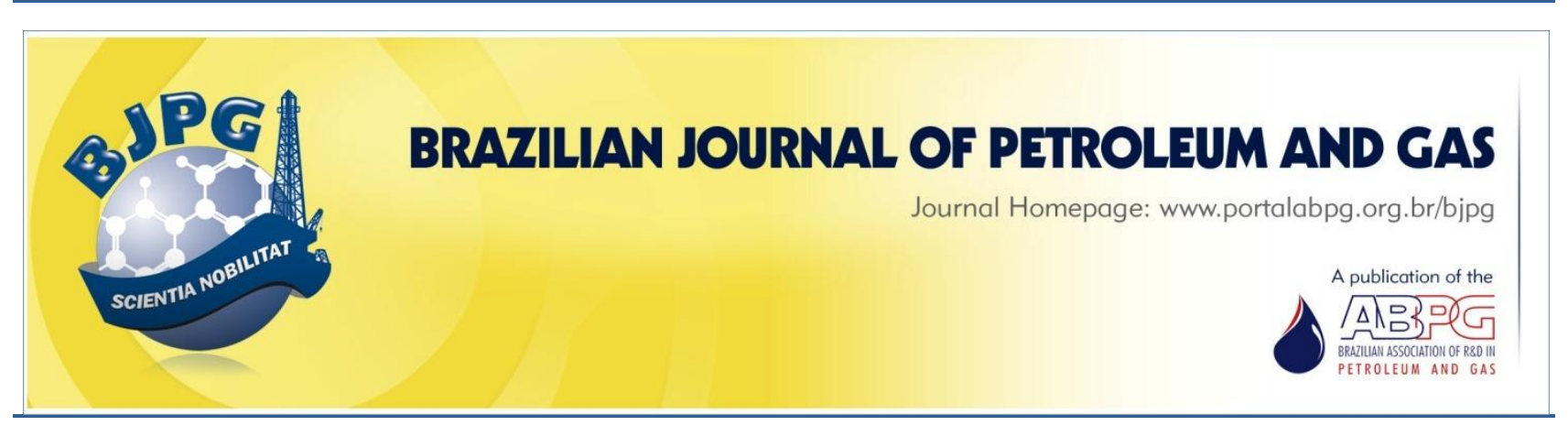

\title{
MODELING AND SIMULATION OF A HORIZONTAL THREE-PHASE SEPARATOR: INFLUENCE OF INLET FLOW
}

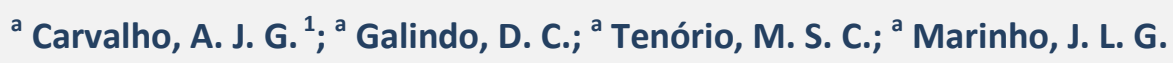 \\ ${ }^{a}$ Federal University of Alagoas, Technology Center, Maceió - AL, Brazil
}

Received: 25.03.2020 / Revised: 27.05.2020 / Accepted: 31.05.2020 / Published on line: 06.10.2020

\begin{abstract}
The fluids produced and transported to the surface by the production manifolds do not have the necessary conditions to be economically viable. Produced fluids consist of at least three fluid phases (oil, water, and gas), besides impurities and contaminants. Therefore, the well stream should be processed as soon as possible after bringing it to the surface. Separator vessels are among the main equipment used at surface production facilities, being responsible for the separation of the produced phases. This work focuses in studying the fluid dynamic behavior in a horizontal three-phase separator. For this, we used the computational fluid dynamics software ANSYS CFX. First, a detailed analysis of a "Standard Case" was performed to better understand the entire separation process within the vessel. The results showed the three phases through simulation time, an analysis of the separation efficiency, an analysis of the different fluids flow lines, an analysis of the pressure gradient inside the vessel, and an analysis of the effect of the diverter baffle, as well as, a variation of fluid flow at the inlet of the separator.
\end{abstract}

\section{KEYWORDS}

separator vessel; computational fluid dynamics; ANSYS CFD

\footnotetext{
${ }^{1}$ To whom all correspondence should be addressed.

Address: Federal University of Alagoas, Technology Center, Lourival Melo Mota Ave., Cidade Universitária, Maceió - AL, Brazil. ZIP Code: 57072.900 | Phone number: +55 2182 3214-1292 | e-mail: augustojgc@gmail.com doi:10.5419/bjpg2020-0012
} 


\section{INTRODUCTION}

Besides being one of the main sources of energy used by our society, oil has a variety of additional uses. Its derivatives are the raw material for the manufacture of numerous products, playing an increasingly important role in people's lives (Mariano, 2001). This mineraloid is originated through the decomposition of organic matter that, under the action of pressure and heat, generates mixtures of compounds consisting mainly of hydrocarbons (Kunert, 2007).

In oil reservoirs, apart from the oil phase, there are the interstitial water and natural gas phases. The occurrence of natural gas, however, will depend on the local pressure condition inside the reservoir (Kunert, 2007). Considering a conventional reservoir (e. g. anticlinal structural traps), it is common to find the oil layer between the water and gas layers inside the reservoir rock. This is mainly due to the difference in density and the immiscibility between the phases.

For this type of reservoir configuration, besides oil and natural gas production, it is common to find produced water, sediments, and contaminating gases, such as $\mathrm{CO}_{2}$ and $\mathrm{H}_{2} \mathrm{~S}$. Generally, the only economic interest resides in oil and gas, reason why they are often called "production facilities." These methods perform the primary processing of fluids with the objective of separating water, oil, and gas; performing the treatment of these phases (Kunert, 2007). A major equipment in a primary processing plant is the separating vessel. These facilities are responsible for separating the different phases produced. These separating vessels can be classified according to their shape (vertical or horizontal) or according to the number of phases to be separated (biphasic or threephased) (Diniz, 2017).

The use of computational fluid dynamics software can be helpful in the study of fluid behavior within a separating vessel. Among these computational programs, the ANSYS CFX is able to simulate the separation of phases in a separating vessel. This allows the visualization of phenomena that occur during the separation process, obtaining pressure, velocity, and residence time profiles, and ensuring the choice of the best configuration for a given project.

The study of various aspects of primary petroleum processing, including the separating vessels, has been conducted by several authors such as Silva (2004), Andrade (2014), and Anjos (2015). When it comes to numerical modeling, literature is more restricted. However, recent studies such as those of Ghaffarkhah et al. (2017), Triwibowo et al. (2017), Scapin et al. (2017), and Ahmed et al. (2019) show the relevance of computer modeling and its potential in industry. All studies mentioned above address Horizontal Three-Phase Separator (HTPS) using Computational Fluid Dynamics (CFD) software.

Ghaffarkhah et al. (2017) studied two semiempiric models, by Arnold and Stewart and by Monnery and Surcek, for dimensioning HTPS, developing a comparative study between them. For the analysis of fluid behavior, the authors used a combination of Volume of Fluid (VOF) and Discrete Particle Method (DPM) models. The work of Triwibowo et al. (2017) focuses on the modeling and simulating a steady-state HTPS. To develop this study, Triwibowo et al. (2017) used the multiphase flow model VOF. Scapin et al. (2018) presented the analysis of a three-phase separator, based on a multifluid eulerian- eulerian model of NavierStokes equations. The aim of these authors was to construct a consistent numerical scheme for the multiphase flow involving more than two phases.

Ahmed et al. (2019) compared two commonly used multiphase flow models, Eulerian and VOF, to predict separation performance and fluid flow patterns in an HTPS. To obtain experimental data, the authors developed two distinct three-phase separator vessels on a pilot scale: one operating at a low flow rate and the other at a high gas volume flow rate. By comparing the results of experimental and numerical data, the authors concluded that numerical simulation is highly recommended to size an industrial scale separator using the appropriate CFD model. Ghaffarkhah et al. (2017), Triwibowo et al. (2017), Scapin et al. (2017), and Ahmed et al. (2019) used their respective multiphase flow models associated with the turbulence model $k-\varepsilon$.

Thus, this work aims to study the fluid dynamic behavior of a three-phase water-on-gas mixture in a horizontal separating vessel, varying the volumetric flow of fluids at the entrance of the separator. Such analysis was performed through simulations in the ANSYS CFX computational fluid dynamics software. 


\section{METHODOLOGY}

For the present work, only one geometry was used for the three-phase horizontal separating vessel. The dimensions used were based on the work of Anjos (2015), with an increase in the total length of the vessel, which is recommended for three-phase separators, because they have sections of accumulation both for oil and water. A lateral view of the separating vessel used as well as its dimensions can be seen in Figure 1. This separating vessel has two internal structures. A diverter baffle near the inlet of fluids and a plate that separates the accumulation sections from the water and gas are shown in Figure 2a. Dimensions of the separator are shown in Figure $2 b$.

\subsection{Mesh generation}

The mesh pattern for this work is unstructured and is formed by 315,936 elements and 56,129 nodes (Figure 3a). This mesh is not completely regular, and, in the smaller parts, such as the plates, entrance and exits (Figure $3 b$ ) have a higher density of elements, providing a better precision of the results.

\subsection{Mathematical modeling}

Each case took an average of one hour to be simulated. This work was performed using the ANSYS Student 18.2 package, which has the ANSYS CFX 18.2 software, the computational fluid dynamics software used to perform the simulations

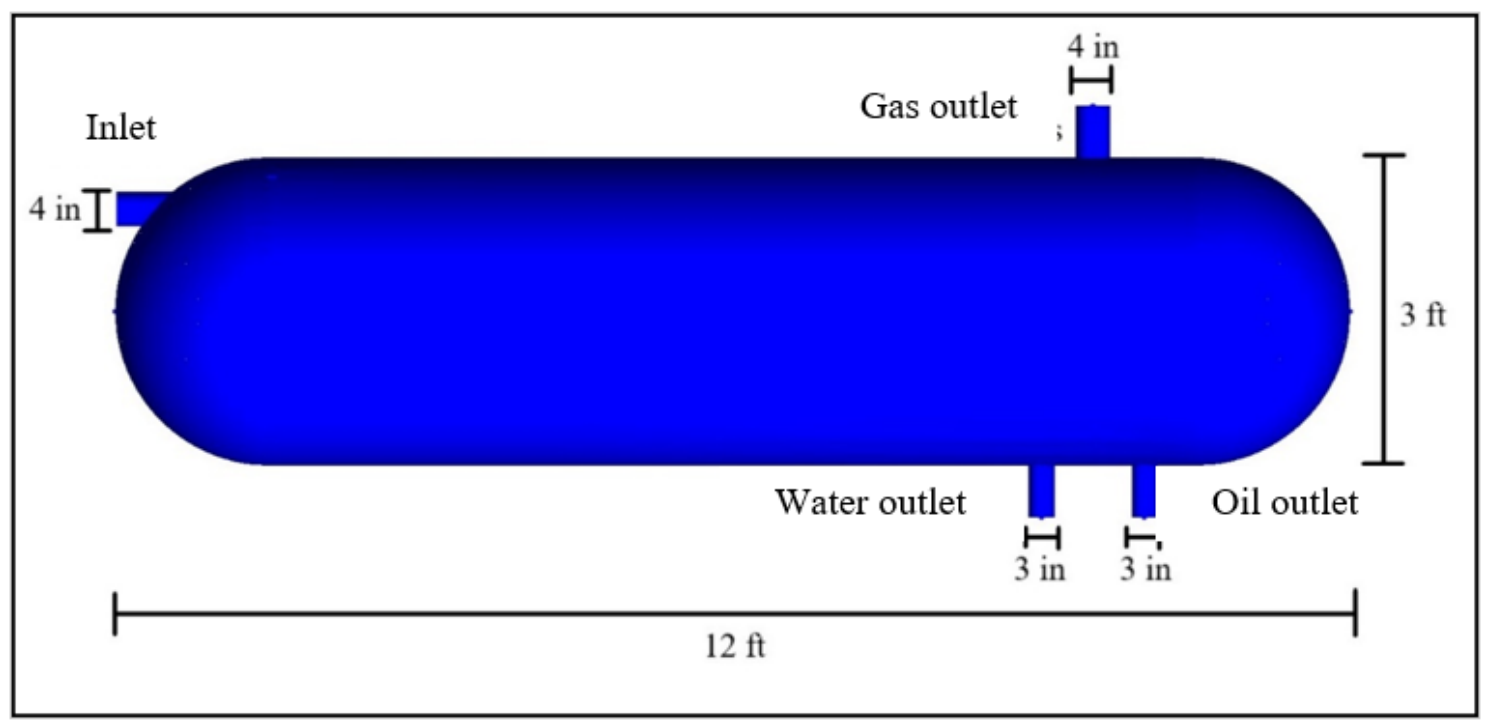

Figure 1. Three-phase horizontal separating vessel (side view).

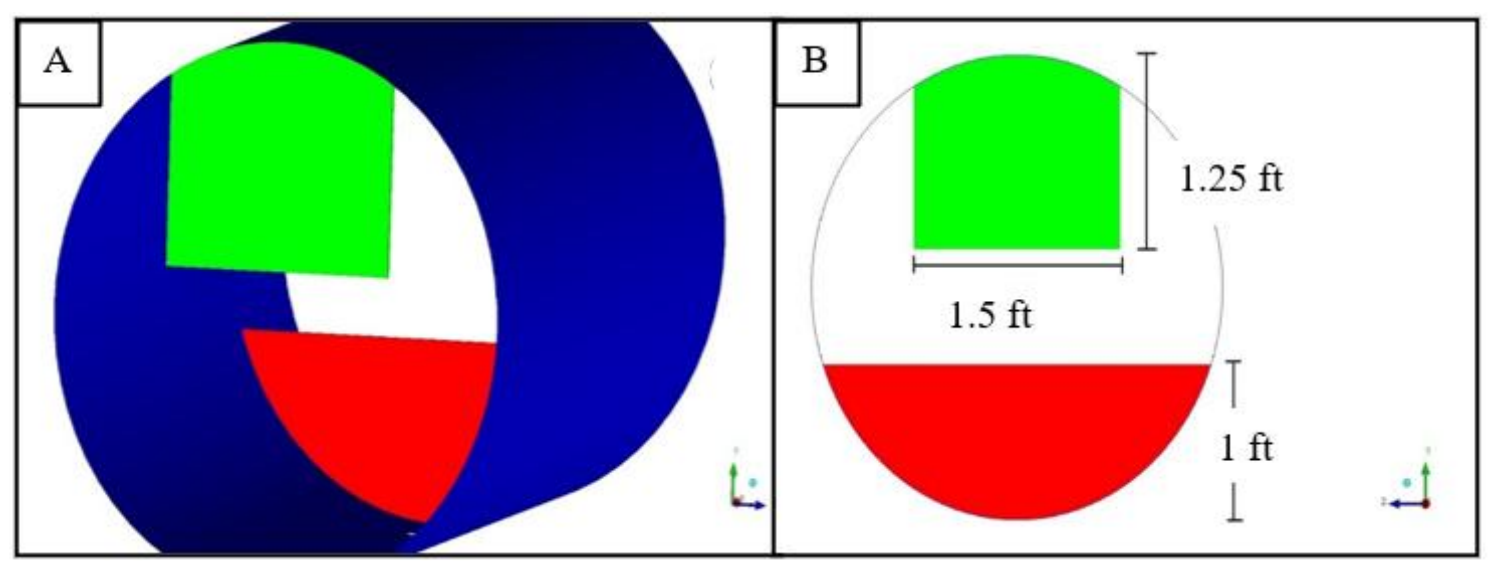

Figure 2. a) Internal structures of the separator and b) separator dimensions. 


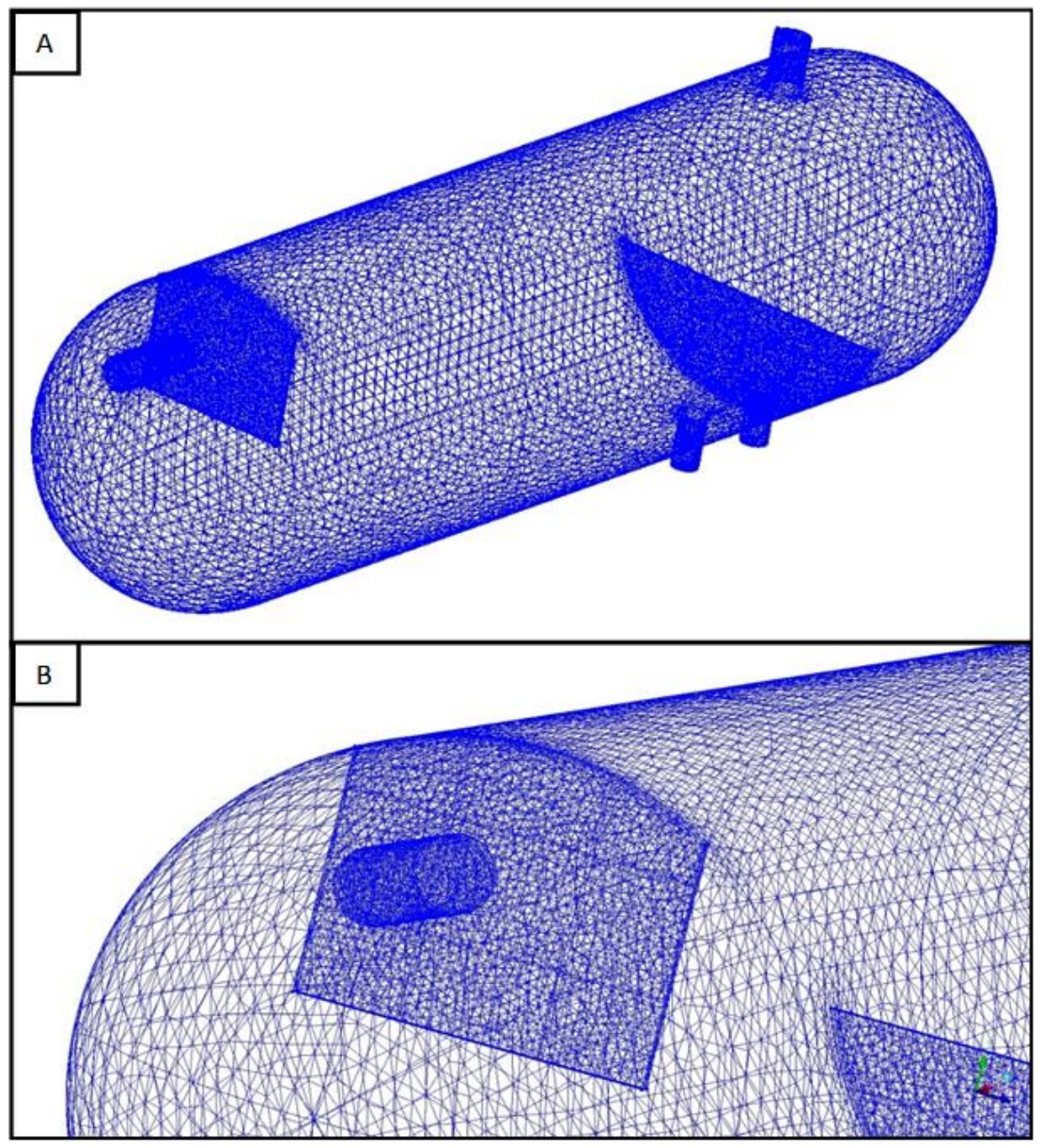

Figure 3. a) Unstructured numerical mesh developed; b) Detailed view of the deflector plate and gas outlet.

and analyze the results. The simulations were performed in a computer with Intel Core i5 quadcore $3.5 \mathrm{GHz}$ processor and $16 \mathrm{~GB}$ of DDR3 1600 RAM.

For the construction of the numerical mesh, ICEM CFD 13.0 was used. This software, which is part of the ANSYS package, is a powerful tool capable of working with both structured and unstructured meshes, from the simplest to the most complex ones. For the mathematical modeling of the problem, we used an EulerianEulerian model, which consists of adopting a time interval, choosing a section or a volume of control in space and considering all the particles that pass through this location (Triwibowo, 2017).

In order to simplify the problem, some hypotheses were considered: 1 ) Slight temperature variation in the analyzed region (isothermal process); 2) Transient regime; 3) Effect of gravity; 4) Three-dimensional domain in Cartesian coordinates; 5) Constant physicochemical properties and no chemical reactions. Through these simplifications it is possible to reduce the number of required equations to three. These equations are applied to each of the control volumes with the use of ANSYS CFX, obtaining a numerical resolution.

\subsection{Fluid domain equations}

In fluid mechanics, the continuity equation, described by Equation 1, determines that the flow with which mass enters a system is equal to the flow with which mass leaves the system plus the accumulated mass. Its form differs is given by: 
$\nabla \cdot\left(r_{\alpha} \rho_{\alpha} \vec{U}_{\alpha}\right)=-\frac{\partial \rho}{\partial t}$

Where:

$r_{\alpha}$ : volumetric fraction of the phase $\alpha$ (adimensional);

$\rho_{\alpha}$ : specific mass of the phase $\alpha$ in $\mathrm{kg} / \mathrm{m}^{3}$;

$\vec{U}_{\alpha}:$ speed of the phase $\alpha$ in $\mathrm{m} / \mathrm{s}$;

$t$ : time in seconds.

The conservation of momentum is described by Equation 2, which encompasses the forces acting on the flow.

$\nabla \cdot\left[r_{\alpha}\left(\rho_{\alpha} \vec{U}_{\alpha} \otimes \vec{U}_{\alpha}\right)\right]+\frac{\partial(\rho V)}{\partial t}=$

$=r_{\alpha} \nabla p+\nabla\left[r_{\alpha}\left(\tau_{\alpha}+\tau_{\alpha}^{t u r b}\right)\right]+\vec{M}_{\alpha}$

Where:

$\mathrm{p}$ : pressure in $\mathrm{Pa}$;

$\Delta p$ : pressure gradient;

$\tau_{\alpha}$ : tension in phase $\alpha$ in $\mathrm{kg} / \mathrm{ms}^{2}$;

$\tau_{\alpha}^{t u r b}$ : turbulent tension of Reynolds in phase $\alpha$ in $\mathrm{kg} / \mathrm{ms}^{2}$;

$\vec{M}_{\alpha}$ : interfacial forces acting in phase $\alpha$ due to the presence of other phases in $\mathrm{N} / \mathrm{m}^{3}$; (3):

The value of $\vec{M}_{\alpha}$ can be calculated from Equation

$\vec{M}_{\alpha}=C_{D} \rho_{\alpha \beta} A_{\alpha \beta}\left|\vec{U}_{\beta}-\vec{U}_{\alpha}\right|\left(\vec{U}_{\beta}-\vec{U}_{\alpha}\right)$

Where:

$\rho_{\alpha \beta}:$ specific mass of mixture in $\mathrm{kg} / \mathrm{m}^{3}$;

$A_{\alpha \beta}$ : specific mass of interfacial area in $\mathrm{m}-1$;

$\vec{U}_{\alpha}$ : speed of phase $\alpha$ in $\mathrm{m} / \mathrm{s}$;

$\vec{U}_{\beta}$ : speed of phase $\beta$ in $\mathrm{m} / \mathrm{s}$;

The value of $A_{\alpha \beta}$ is defined as a function of the dispersed fraction and the diameter of the particles according to Equation (4):

$A_{\alpha \beta}=\frac{6 r_{\beta}}{d_{\beta}}$
Where:

$\mathrm{r}_{\beta}$ : fraction of dispersed phase (adimensional);

$d_{\beta}$ : diameter of phase particles $\beta$ (adimensional).

\subsection{Turbulence Model}

For this work, the k- $\varepsilon$ turbulence model was used. This model involves the modeling of two differential transport equations, one for turbulent kinetic energy $k$ and the other for $\varepsilon$, which represents the rate of dissipation of turbulent kinetic energy per unit of mass. This is a very popular turbulence model, providing a good relationship between computational effort and accuracy. It is represented by equations (5) and (6).

$$
\begin{aligned}
& \nabla(\rho \vec{U} k)=\nabla\left[\left(\mu+\frac{\mu_{t}}{\sigma_{k}}\right) \nabla k\right]+\left(P_{k}-\rho \varepsilon\right) \\
& \nabla(\rho \vec{U} k)=\nabla\left[\left(\mu+\frac{\mu_{t}}{\sigma_{\varepsilon}}\right) \nabla \varepsilon\right]+\frac{\varepsilon}{k}\left(C_{\varepsilon 1} P_{k}-C_{\varepsilon 2} \rho \varepsilon\right)
\end{aligned}
$$

Where:

$\varepsilon$ : rate of turbulent dissipation in $\mathrm{m}^{2} / \mathrm{s}^{3}$;

$k:$ turbulent kinetic energy in $\mathrm{kg} \cdot \mathrm{m}^{2} / \mathrm{s}^{2}$;

$\mu$ : dynamic viscosity in N.s $/ \mathrm{m}^{2}$;

$\mu_{t}$ : turbulent viscosity in N.s/ $\mathrm{m}^{2}$;

$\sigma_{k}, \sigma_{\varepsilon} e C_{\varepsilon}$ : dimensional constants of turbulence model k- $\varepsilon$.

\subsection{Boundary conditions and fluids properties}

In this paper, the efficiency of fluid separation is evaluated in several situations through the modification of some variables. The standard operating conditions were $25{ }^{\circ} \mathrm{C}$ of temperature and 17.2 bar of pressure. The fluid properties for such conditions are shown in Table 1.

To make the operating conditions of the separating vessel in the standard case consistent with reality, both the maximum gas and liquid capacity were calculated. The gas and liquid capacities are represented, respectively, by Equations 7 and 8. Equation 7, proposed by Souders-Brown, is empirical and does not consider the length of the vessel and the level of liquid inside it. 
Table 1. Properties of fluids in standard conditions.

\begin{tabular}{|c|c|c|c|}
\hline & Oil & Gas & Water \\
\hline Specific Mass & $813,464 \mathrm{~kg} / \mathrm{m}^{3}$ & $0.7236 \mathrm{~kg} / \mathrm{m}^{3}$ & $997 \mathrm{~kg} / \mathrm{m}^{3}$ \\
\hline Dynamic Viscosity & $0.021 \mathrm{~kg} / \mathrm{ms}$ & $1.08 \mathrm{E}-05 \mathrm{~kg} / \mathrm{ms}$ & $8.899 \mathrm{E}-04 \mathrm{~kg} / \mathrm{ms}$ \\
\hline Surface Tension & $0.072 \mathrm{~N} / \mathrm{m}$ & - & $0.072 \mathrm{~N} / \mathrm{m}$ \\
\hline Constant Pressure Heat Capacity & $2140 \mathrm{~J} / \mathrm{kg} . \mathrm{K}$ & - & $4181 \mathrm{~J} / \mathrm{kg} . \mathrm{K}$ \\
\hline Average Droplet Diameter & $100 \mu \mathrm{m}$ & - & $100 \mu \mathrm{m}$ \\
\hline
\end{tabular}

$q_{s t}=\frac{2,4 D^{2} K p_{o p}}{z(T+460)} \sqrt{\frac{\rho_{L}-\rho_{g}}{\rho_{g}}}$

Where:

$q_{s t}:$ gas capacity at standard conditions in MMscfd;

$D$ : inner diameter of the vessel in $\mathrm{ft}$;

$p_{o p}$ : operating pressure in psia;

$T$ : operating temperature in ${ }^{\circ} \mathrm{F}$;

$z$ : gas compressibility factor (adimensional);

$\rho_{L}$ : specific mass of the liquid under operating conditions in $\mathrm{lbm} / \mathrm{ft}^{3}$;

$\rho_{g}$ : specific mass of the gas under operating conditions in $\mathrm{lbm} / \mathrm{ft}^{3}$;

$K$ : empirical factor (adimensional).

$q_{L}=\frac{1440 V_{L}}{t}$

Where:

$q_{L}:$ liquid capacity in $\mathrm{bbl} / \mathrm{d}$;

$V_{L}$ : sedimentation volume of liquid in bbl;

$t_{r}$ : retention time in minutes.

In the boundary conditions, a mixture with $92 \%$ gas and $8 \%$ liquids, divided into oil (6\%) and water (2\%) was considered for the inlet (Nakayama, 1999). In the vessel walls $(0.0456 \mathrm{~mm}$ of medium roughness), and in deflector and separator plates, the slip wall condition was admitted, in which the relative velocity of the fluid in relation to the wall is null.
The gas outlet is of the opening type, with standard relative pressure. For the liquid outlet, a constant and negative velocity of $0.25 \mathrm{~m} / \mathrm{s}$ was applied. The initial condition of the vessel considered that the vessel was full, with an oilwater mixture composed of $50 \%$ of each phase up to $2 / 3$ of the height, the rest being filled with gas.

All simulations were performed in a transient regime with a maximum number of 20 loops for each iteration. Each case was simulated for a total time of 20 minutes with time steps of 10 seconds having a convergence criterion of $10-4 \mathrm{~kg} \cdot \mathrm{s}^{-1}$.

\subsection{Case study analysis}

\subsubsection{Standard case}

For the standard case that was used as a basis for further studies, an input velocity of $13 \mathrm{~m} / \mathrm{s}$ (flow rate of $0.105395 \mathrm{~m}^{3} / \mathrm{s}$ ) with fractions of $92 \%$ gas, $6 \%$ oil, and $2 \%$ water was considered. Physicalchemical properties are demonstrated in Table 2. This results in a flow rate of $3436.71 \mathrm{bbl} /$ day of oil, $1145.57 \mathrm{bbl} /$ day of water, and $0.3 \mathrm{MMscfd}$ of gas.

\subsubsection{Fluid flow variation}

This case analyzed the influence of the fluid flow increase in the inlet on the fluid dynamic behavior of the separator. For all cases presented in Table 2, an input mixture with $92 \%$ gas, $6 \%$ oil and $2 \%$ water by volume was considered.

Besides the standard case and the analysis of the fluid flow variation, other studies can be done. Among them, the variations of the gas/liquid ratio, oil/water ratio, and the physical-chemical properties of the produced oil. 
Table 2. Variation of fluid flow at the separator inlet.

\begin{tabular}{cccccc}
\hline Simulation & $\begin{array}{c}\text { Input Speed } \\
(\mathbf{m} / \mathbf{s})\end{array}$ & $\begin{array}{c}\text { Input Flow } \\
\left(\mathbf{m}^{\mathbf{3}} \mathbf{s}\right)\end{array}$ & $\begin{array}{c}\text { Oil Flow } \\
\text { (bbl/dia) }\end{array}$ & $\begin{array}{c}\text { Water Flow } \\
\text { (bbl/dia) }\end{array}$ & Gas Flow (MMscfd) \\
\hline 1 & 13 & 0.105395 & 3436.71 & 1145.57 & 0.3 \\
2 & 15 & 0.12161 & 3965.48 & 1321.65 & 0.34 \\
3 & 17 & 0.137824 & 4493.70 & 1497.72 & 0.39 \\
\hline
\end{tabular}

\section{RESULTS AND DISCUSSION}

First, we performed a detailed analysis of the Standard Case. Afterwards, we discussed the results of the other cases, analyzing the influence of fluid flow variations.

\subsection{Standard case}

Figures 4, 5, and 6 show, respectively, the volumetric fractions of oil, water, and natural gas inside the separator over 20 minutes.

After the analysis of Figures 4, 5, and 6, one can see that the separator worked out as expected. At the end of the simulation, the separation of the three phases inside the equipment was obtained, as well as the flow of the required fluids in the three outlets of the separator vessel. This behavior is very similar to those obtained by Ghaffarkhah et al. (2017) and Triwibowo et al. (2017).

Through the results obtained some visual and numerical observations can be made:

I. In the first minute it is possible to observe a considerable drop in the level of liquid inside the vessel. During this time there is still no stabilization of the flow in the water and oil outlets. Subsequently, the velocities at the outlets stabilize at $0.25 \mathrm{~m} / \mathrm{s}$, the value established by the modeling's boundary conditions. During the rest of the process, the liquid level remained basically constant, a

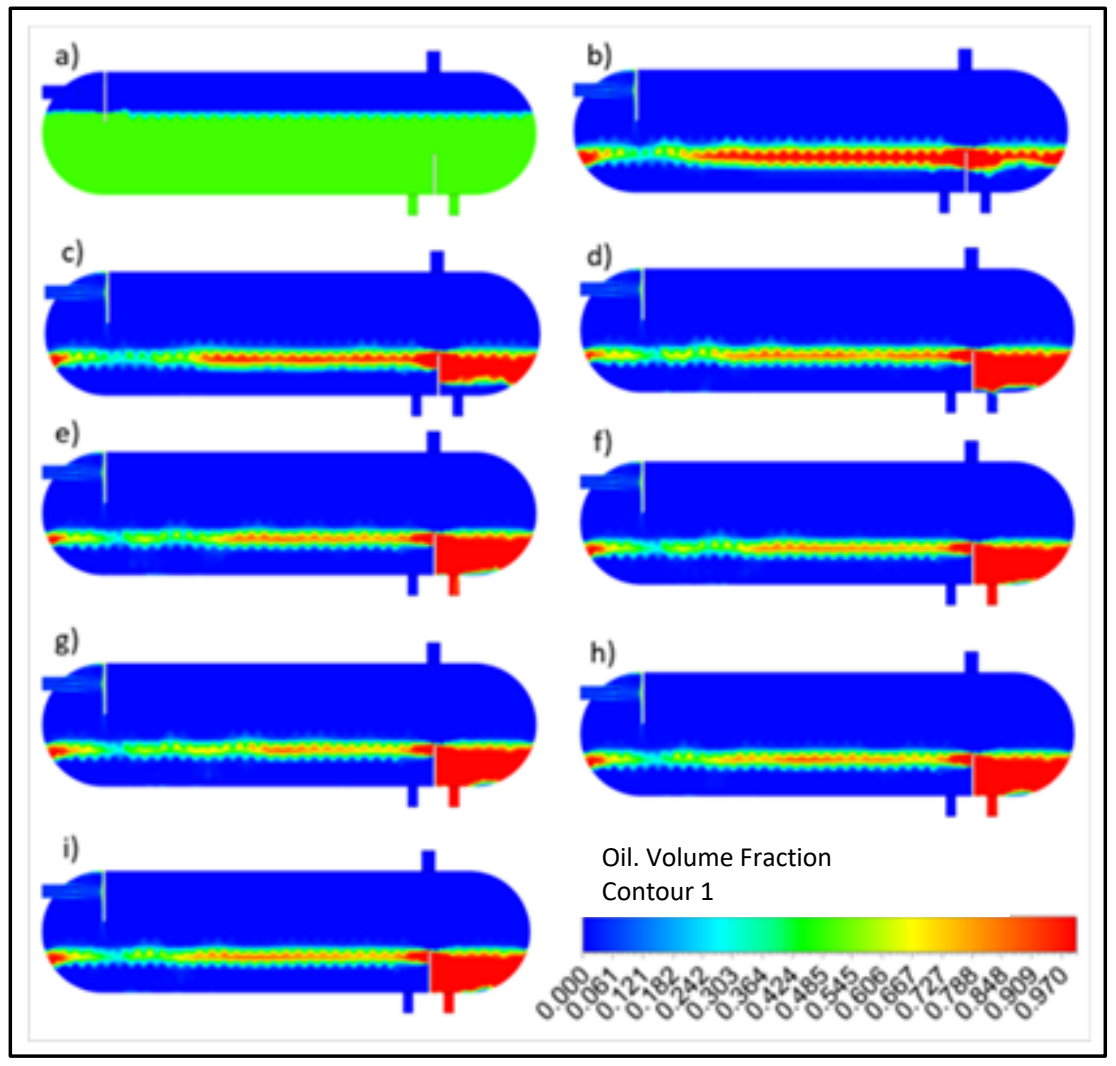

Figure 4. Oil volumetric fraction in a) $0 \mathrm{~s}$, b) $150 \mathrm{~s}, \mathrm{c}) 300 \mathrm{~s}$, d) $450 \mathrm{~s}, \mathrm{e)} 600 \mathrm{~s}, \mathrm{f}) 750 \mathrm{~s}, \mathrm{~g}) 900 \mathrm{~s}, \mathrm{~h}) 1050 \mathrm{~s}$, and i) $1200 \mathrm{~s}$. 


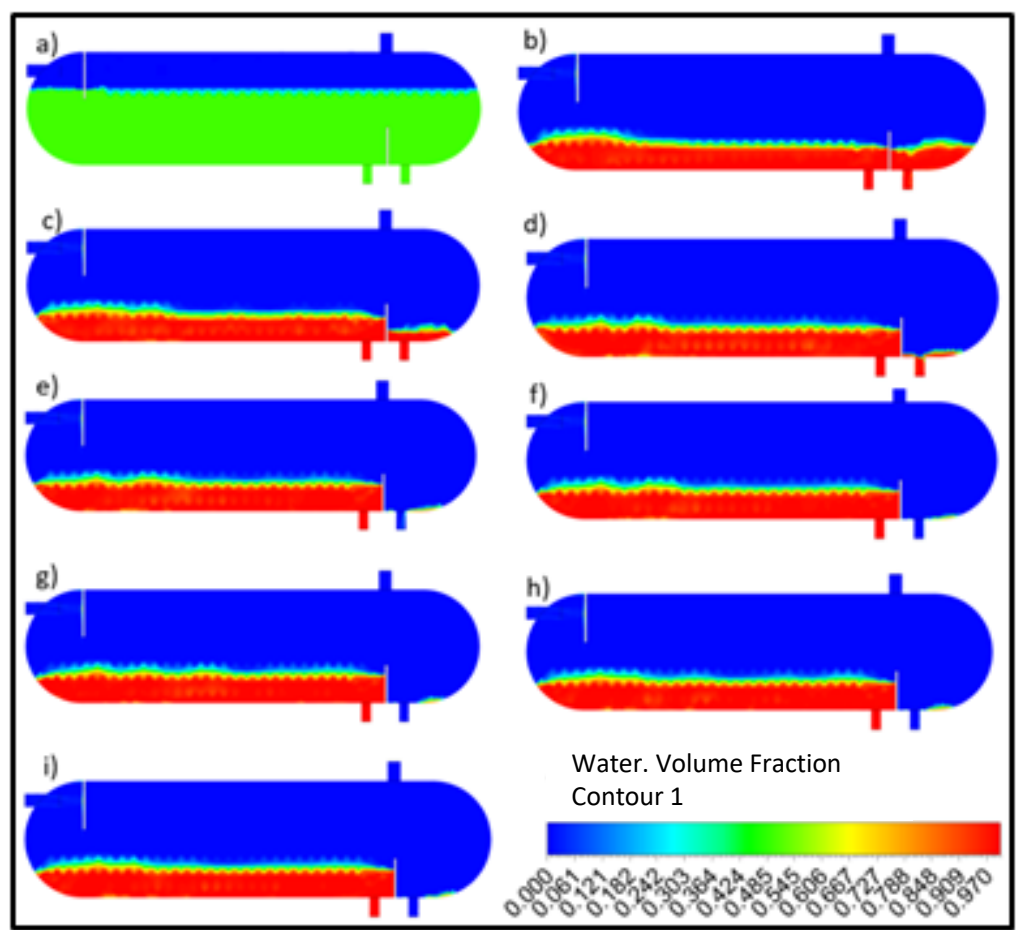

Figure 5. Water volumetric fraction a) $0 \mathrm{~s}$, b) $150 \mathrm{~s}$, c) $300 \mathrm{~s}$, d) $450 \mathrm{~s}$, e) $600 \mathrm{~s}$, f) $750 \mathrm{~s}, \mathrm{~g}) 900 \mathrm{~s}, \mathrm{~h}) 1050 \mathrm{~s}$, and i) $1200 \mathrm{~s}$.

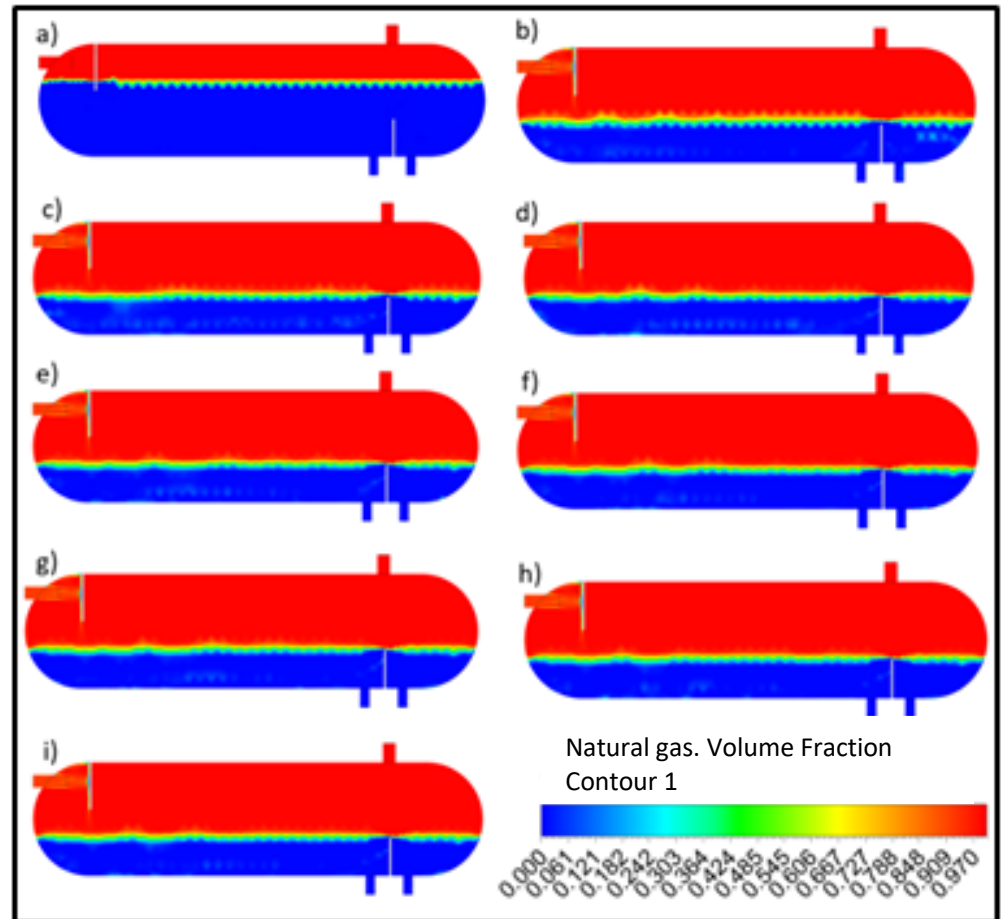

Figure 6. Natural gas volumetric fraction in a) $0 \mathrm{~s}$, b) $150 \mathrm{~s}, \mathrm{c}) 300 \mathrm{~s}$, d) $450 \mathrm{~s}$, e) $600 \mathrm{~s}, \mathrm{f}) 750 \mathrm{~s}, \mathrm{~g}) 900 \mathrm{~s}, \mathrm{~h}) 1050 \mathrm{~s}$, and i) $1200 \mathrm{~s}$.

little above the height of the over-flow inlet diverter between the liquid separation sections. This allowed the oil to flow continuously into the oil collection section, which allowed the equipment to operate properly.
II. Although the separation of the components was relatively quick, the equipment took a considerable amount of time to reach a steady state condition. Only after approximately 470 seconds it was possible to obtain more oil than water at the oil outlet. 
After 520 seconds, the oil fraction came closer to the intended one, reaching about $90 \%$.

III. Even after the separation process had stabilized and the vessel had begun to operate continuously, it was possible to notice a small accumulation of water at the bottom of the oil storage section, as shown in Figure 7.

IV. After equipment stabilization, the separation of phases did not happen completely. It was possible to observe traces of oil in the water accumulation section (Figure 8) and the presence of gas dispersed in the liquid phase

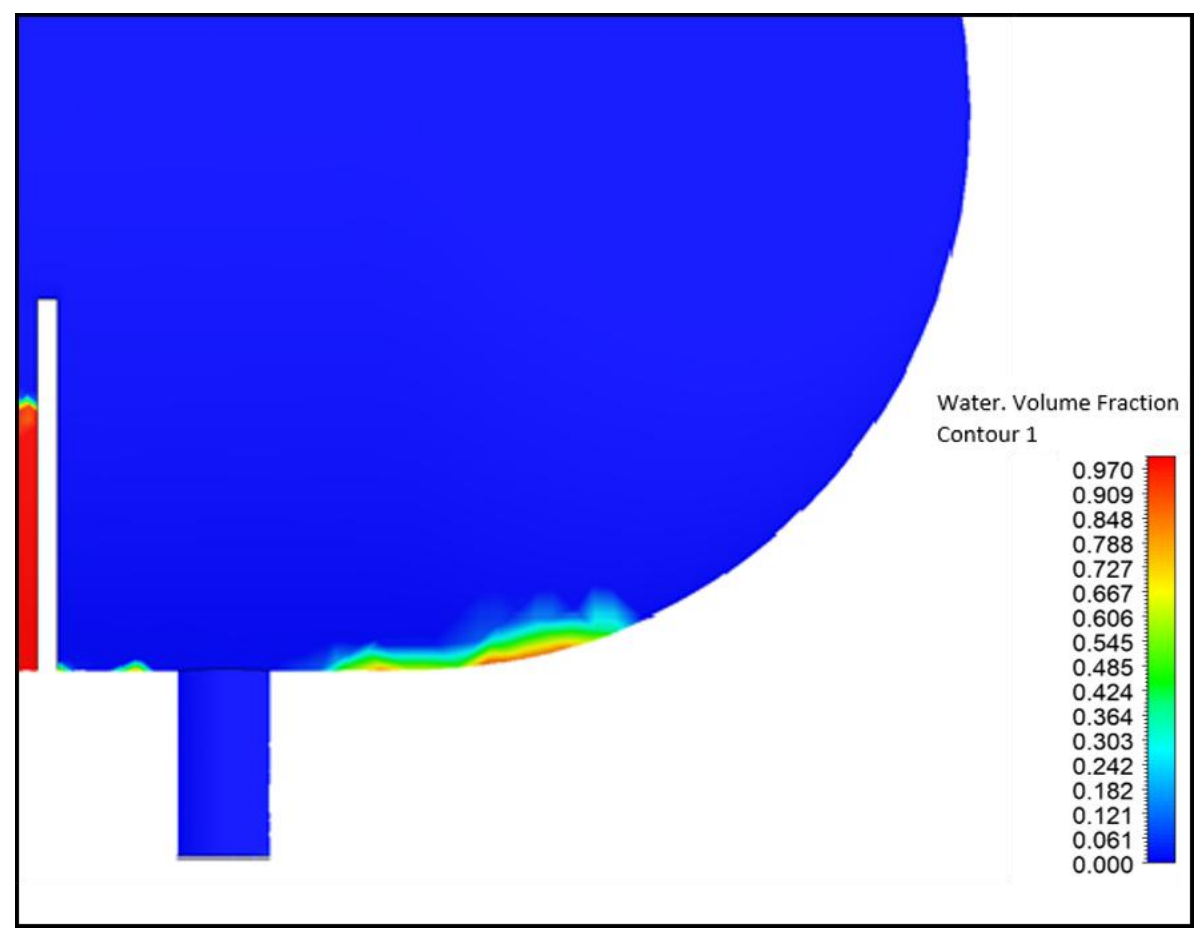

Figure 7. Detail of water accumulation in the oil accumulation section (1200 s).

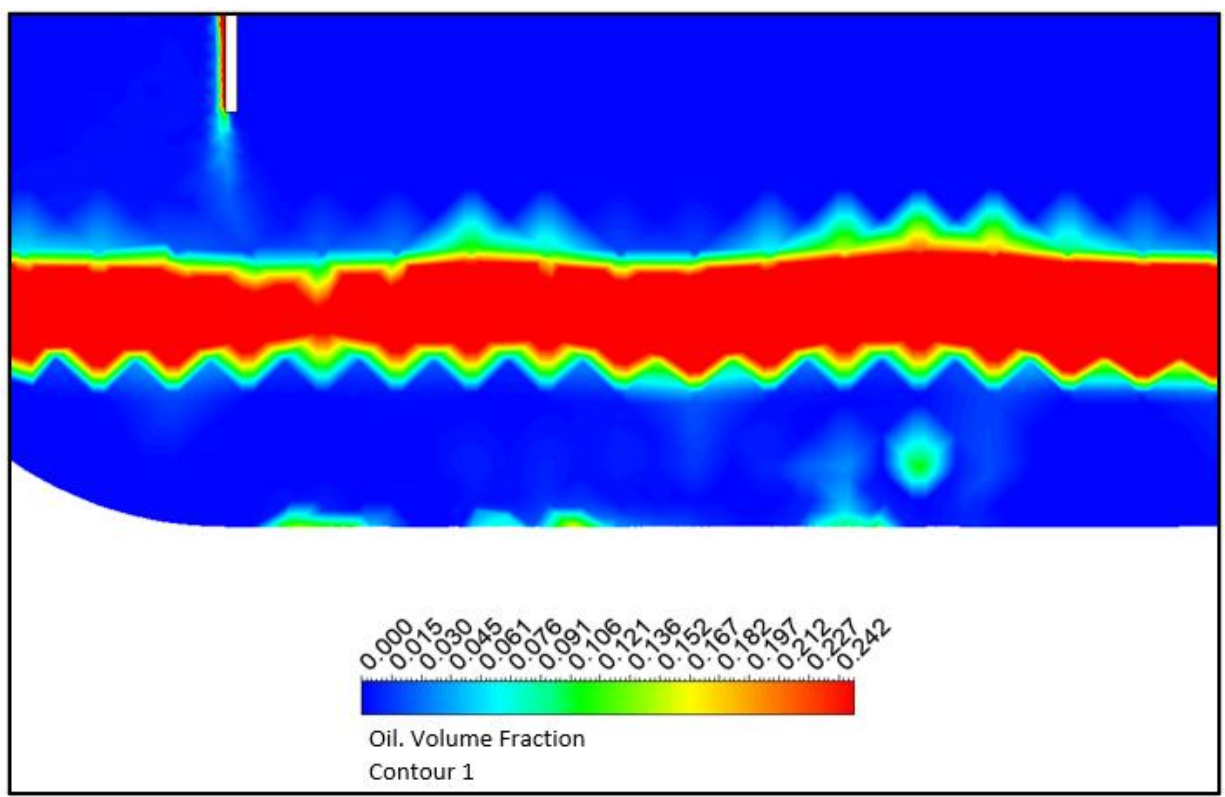

Figure 8. Traces of oil in the water accumulation section (1090 s). 


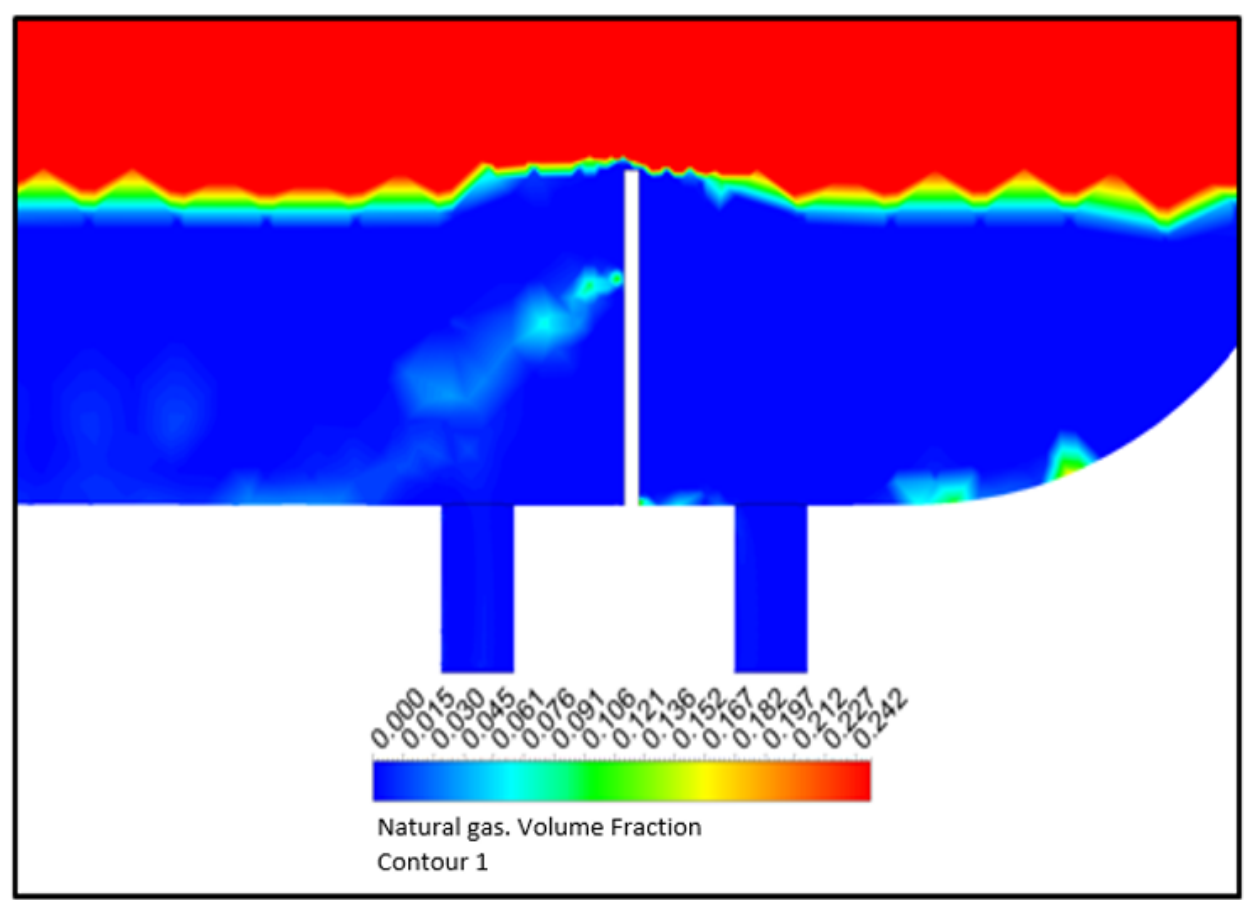

Figure 9. Gas traces in liquid accumulation sections (660 s).

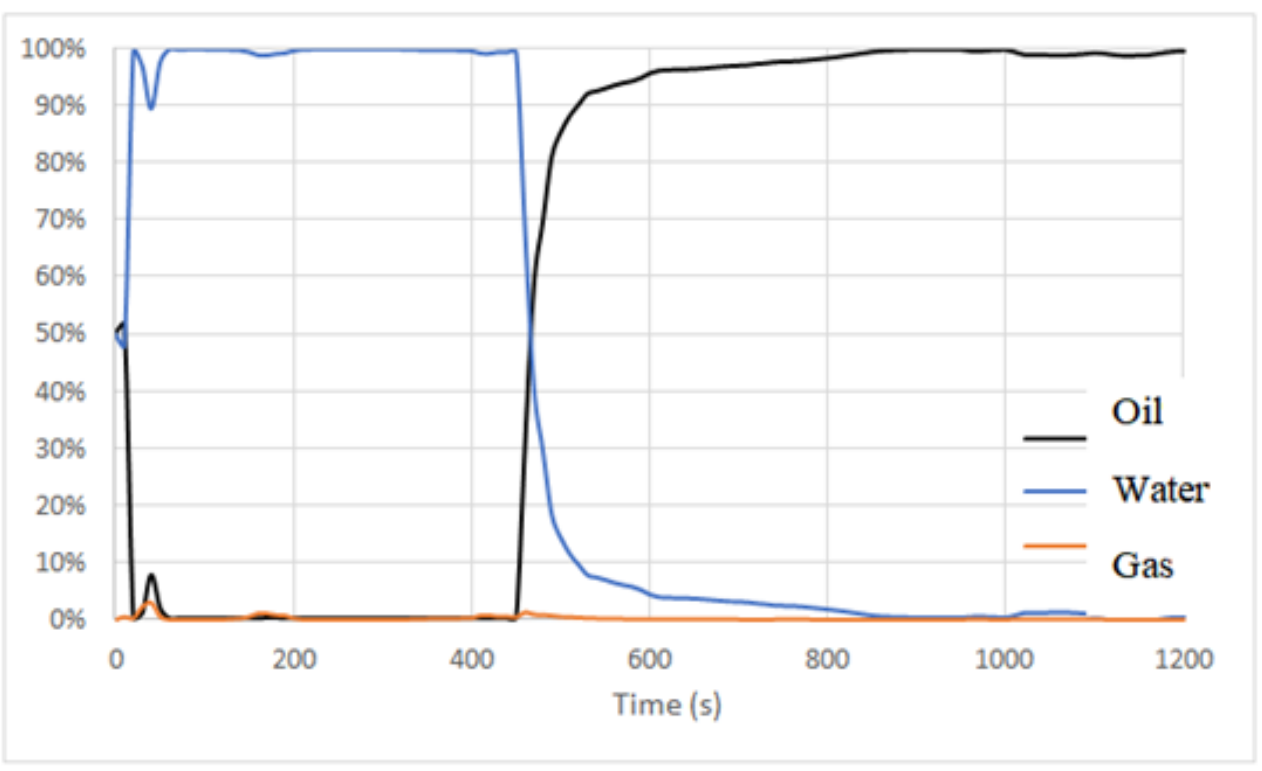

Figure 10. Graph that shows the volumetric fractions of oil, water and natural gas at the oil outlet.

(Figure 9). In the first case, because of the low flow velocity at the water outlet and the long period for which the mixture is retained, it was not possible to notice traces of oil in the outlet most of the time. In the second case, it was not possible to avoid completely the gas drag through the liquid phases. Fortunately, dragging was limited, not compromising the process, with an average gas fraction of only $0.0322 \%$ at the water outlet and $0.2046 \%$ at the oil outlet.

\subsection{Separation efficiency analysis}

\subsubsection{Oil inlet}

Usually, oil is the one phase that has the highest economic value if compared to the other phases. Therefore, it is relevant that the largest amount of volumetric fraction of this component is drained. The Figure 10 shows the volumetric fraction of the three components in the oil outlet throughout the 20 minutes of simulation. 
During about 450 seconds, there is a predominance of water flow. After this moment, the oil finally starts to flow, inverting the oil and water fraction afterwards. Throughout the process, the amount of gas in the outlet remains practically constant.

Figures 11, 12, and 13 show the volumetric fraction of oil, water, and gas, respectively, in the last 10 minutes of simulation, when the separator is already stabilized and working continuously.

The graphs show that in this simulation period the oil fraction always remains above 95\%, reaching a maximum value of $99.8871 \%$ at 940 seconds. At the end of the simulation, a fraction of $99.6074 \%$ of oil is observed. Between 900 and 1150 seconds, there is a slight decrease in the oil fraction, and this is due to the movement of water accumulation in the oil accumulation section. When the water moves to the left, it approaches the oil outlet and ends up draining a little. Thereafter, the accumulation moves to the right, causing the oil fraction in the oil outlet to increase.

Even after the settling period of the separator, it was not possible to completely avoid gas dragging

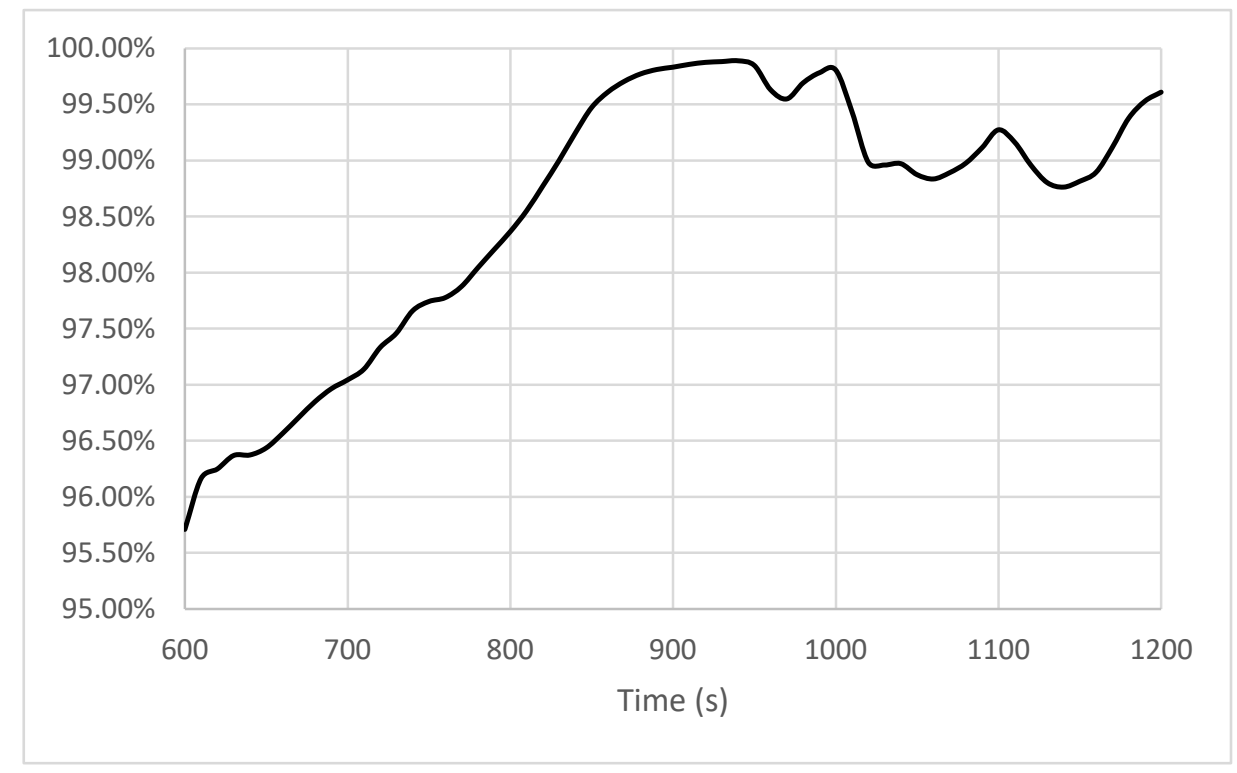

Figure 11. Graph that shows the volumetric fraction of oil at the oil outlet in the last 10 minutes (600 s).

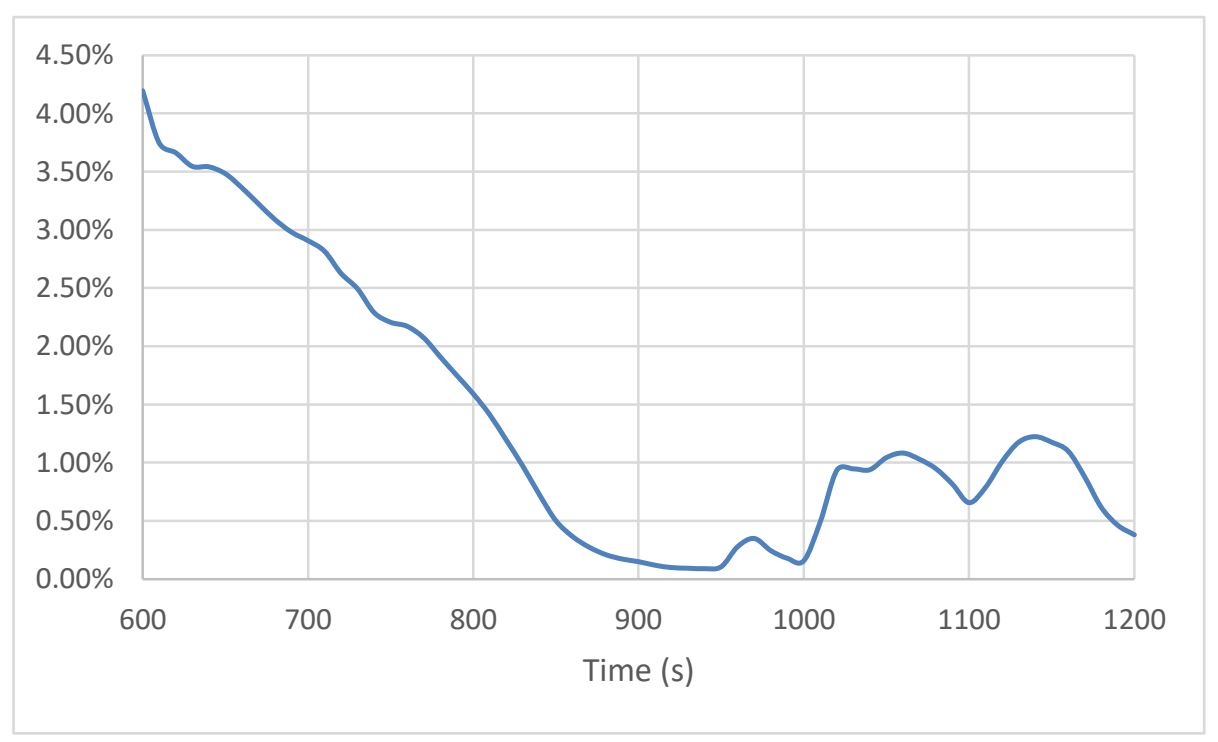

Figure 12. Graph that shows the volumetric fraction of water at the oil outlet in the last 10 minutes (600 s). 


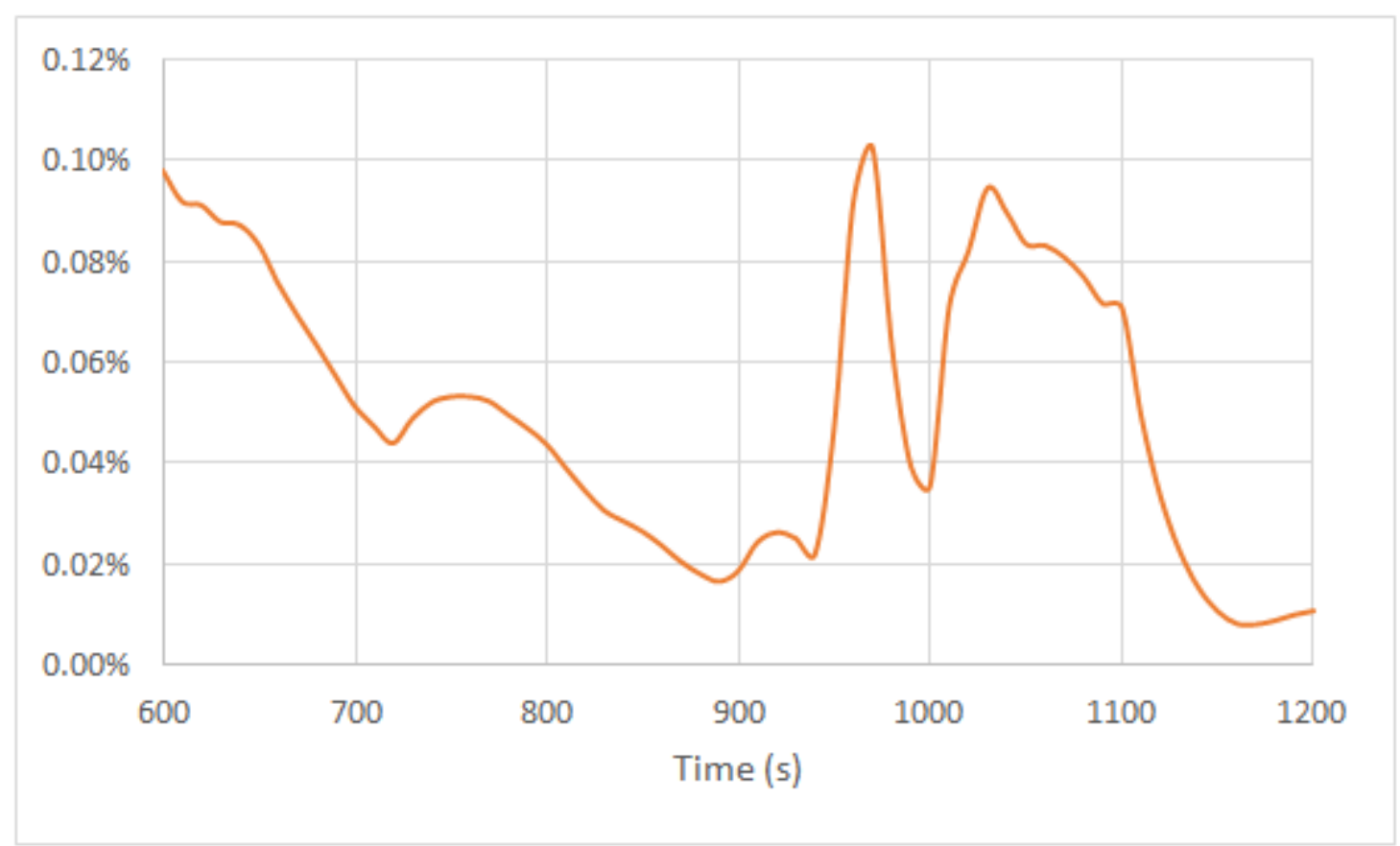

Figure 13. Graph that shows the volumetric fraction of natural gas at the oil outlet in the last 10 minutes (600 s).

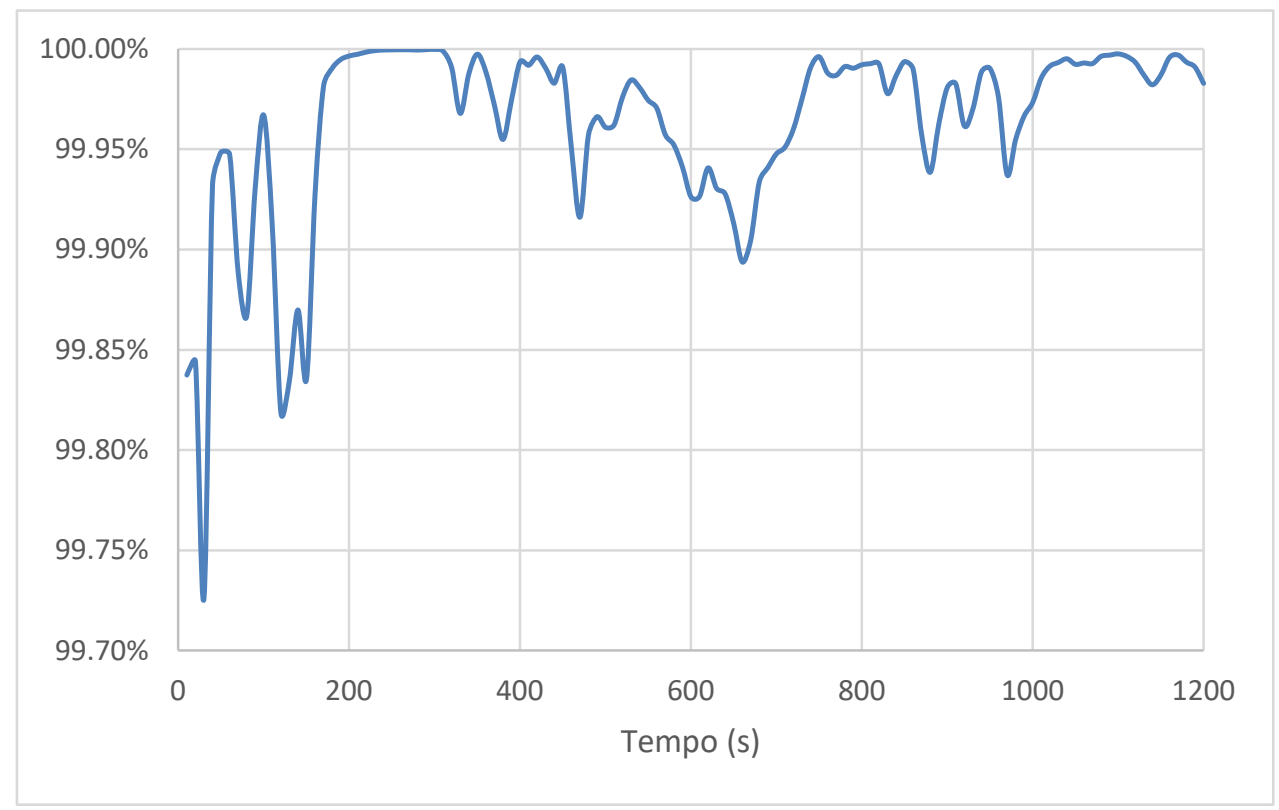

Figure 14. Graph that shows the volumetric fraction of water at the water outlet in the 20 minutes of simulation.

through the oil. Although the natural gas corresponds to $92 \%$ of the fluid intake in the separator, the amount produced at the oil outlet is not large enough to compromise the process, since the volumetric fraction of this component is almost always below $0.1 \%$, as shown in Figure 13 .

\subsubsection{Water outlet}

Despite not having a significant economic value, the produced water shall contain as little oil and contaminants as possible to satisfy environmental standards for both reutilization and disposal. Figure 14 shows the volumetric fraction of produced 
water at the water outlet over the 20 minutes of simulation.

Looking at the graph, it is possible to notice that the amount of contaminants was very low at all simulation times, never reaching more than $0.3 \%$ in volume. The presence of oil in the water was insignificant, and the drag of gas through the water stayed at an average of only $0.0322 \%$. In this regard, the considerable difference in density between the water and other fluids, as well as the low speed of the streams in the water accumulation section, contributed to this.

\subsubsection{Gas outlet}

Although it usually does not have the same economic value as oil, natural gas is still very important. Natural gas can be used as an energy source and also in secondary recovery, being reinjected in wells to increase hydrocarbon recovery. The gas obtained at the outlet of the separator should be as pure as possible.

In the case analyzed, it was only possible to observe the liquid drag by gas in the first minute, which can be explained by the high level of liquids at the beginning of simulation. After that moment, $100 \%$ gas flow was observed at the outlet. Not only the large difference in density between the gas and liquids contributed to this, but also the shock of the inlet flow on the inlet diverter, the main responsible for the inertial separation between the phases.

\subsection{Pressure analysis}

A pressure analysis was performed inside the separator. Figure 15 shows a graphical representation of the analysis. There was no significant variation in the pressure gradient during most of the simulation time. This occurred because the liquid level remained practically constant, as well as the flow velocity through the liquid outlets, which was fixed at $0.25 \mathrm{~m} / \mathrm{s}$. The average pressure at the water outlet was 17.25 bar. Although the flow velocity at both outlets was the same, the higher density of the water contributed to the slight pressure difference.

\subsection{Streamlines analysis}

Figure 16 shows the streamlines for the oil phase, highlighting surface speed and volumetric fraction. By looking at the images, one can observe that the oil, after the shock with the inlet diverter, loses speed considerably, only increasing again in the region near the outlet. As it descends with low speed, the oil does not invade much the regions of water and gas, presenting a tendency to stay between the fluids.

In the water accumulation section, it is possible to see some circular movements in the region closest to the inlet, where the speed is slowed down by the oil dragging, which is more viscous, at the interface with water. However, the low speed and distance from the water outlet prevented these movements from impairing the equipment's

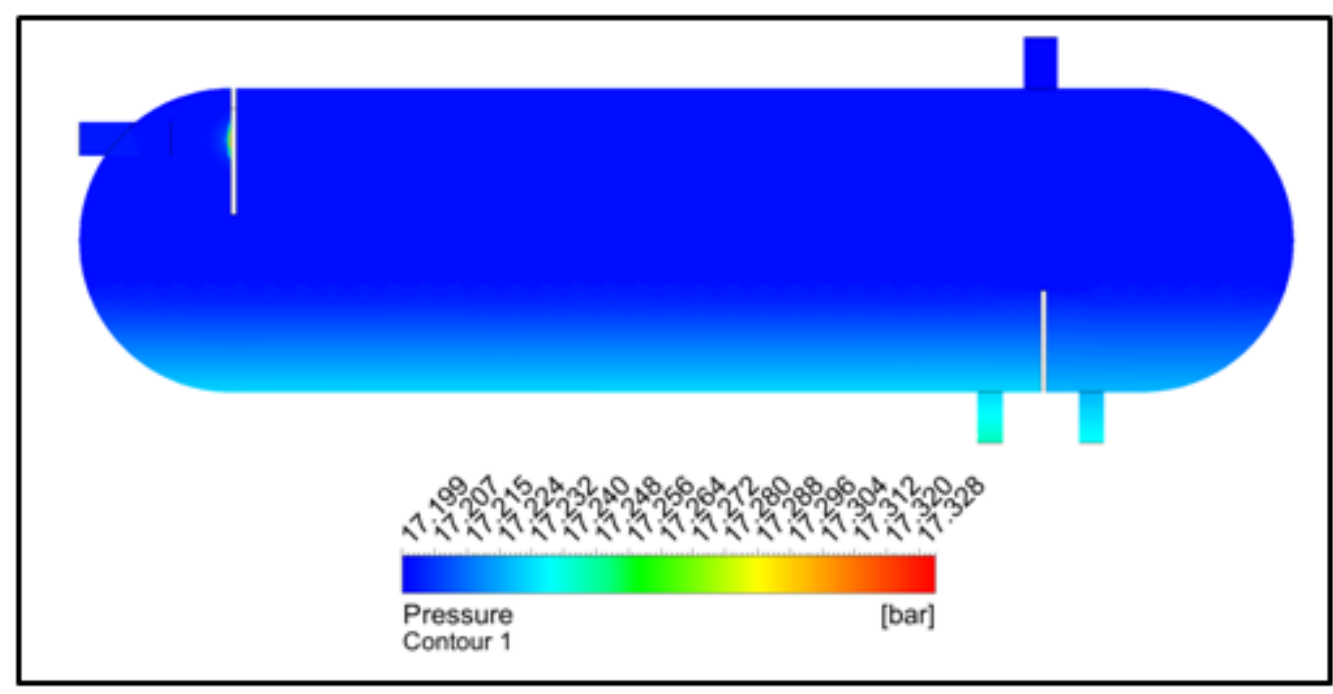

Figure 15. Pressure inside the separating vessel (1200 s). 


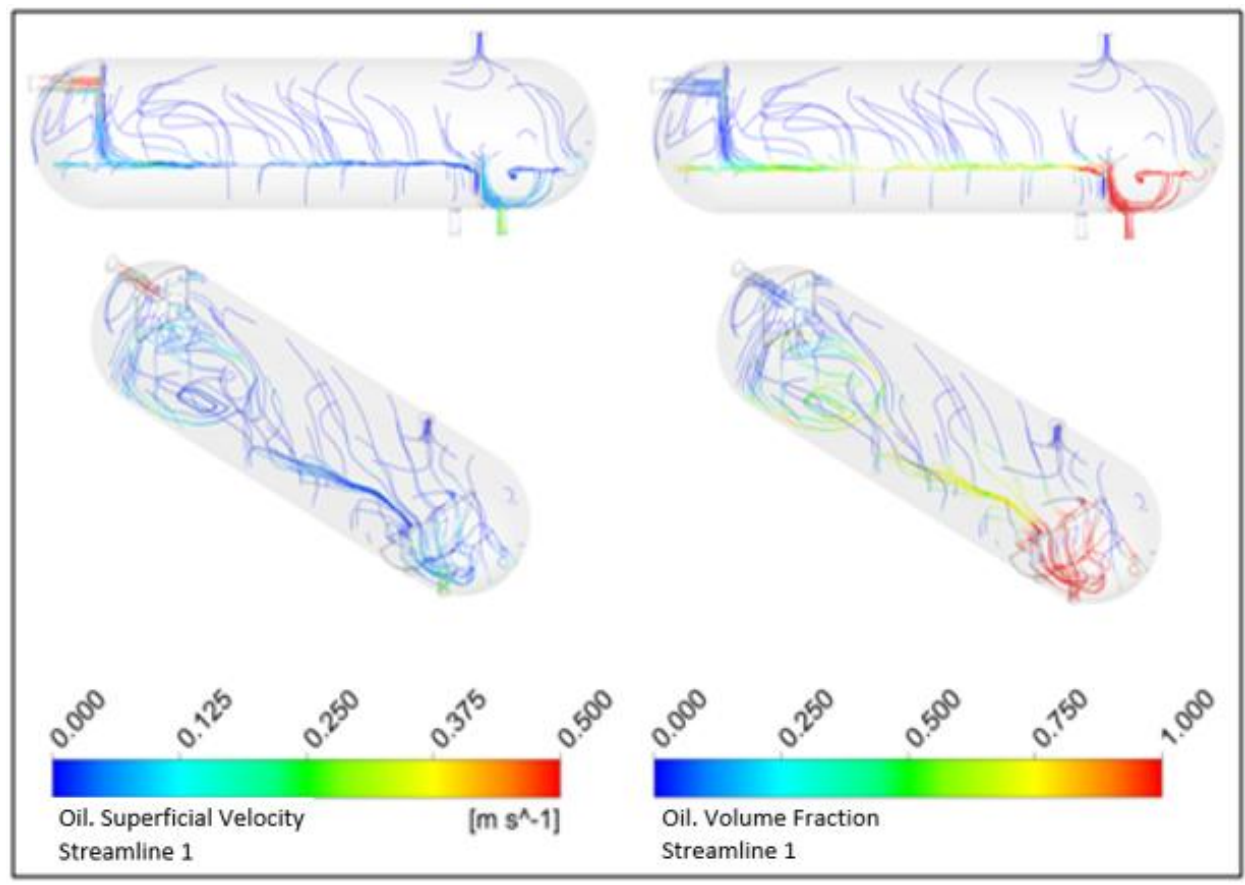

Figure 16. Oil phase streamlines (1200 s).

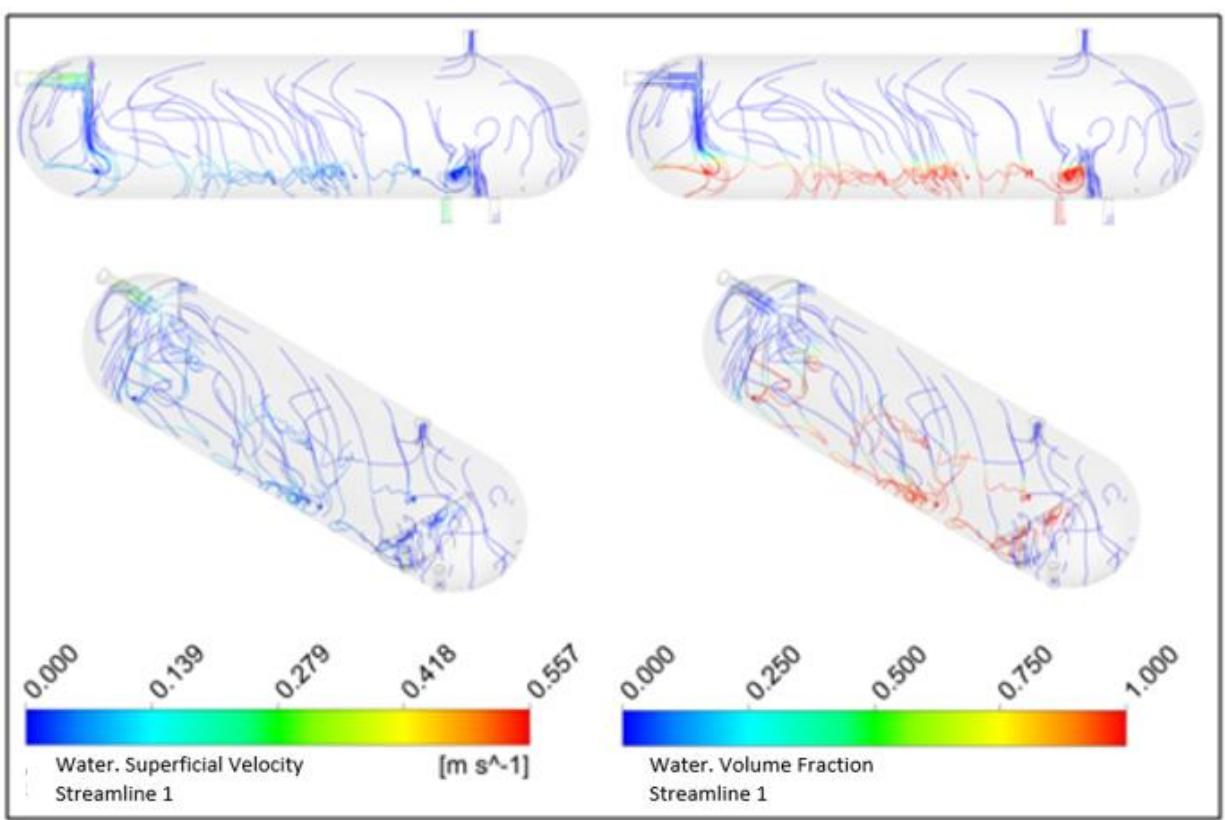

Figure 17. Water phase streamlines (1200 s).

operation. In the oil accumulation section, it is possible to see a more intense movement in a semicircle form. This turbulence may have been responsible for the presence of water accumulation in the bottom, as shown in Figure 7.

Figure 17 presents the streamlines of the water phase, highlighting surface speed and volumetric fraction. When compared to oil streamlines, the water ones present a very similar velocity drop, but the behavior inside the vessel is quite different, showing several small swirls in the water accumulation section and others more severe close to the outlet due to the shock of the water on the overflow baffle. 


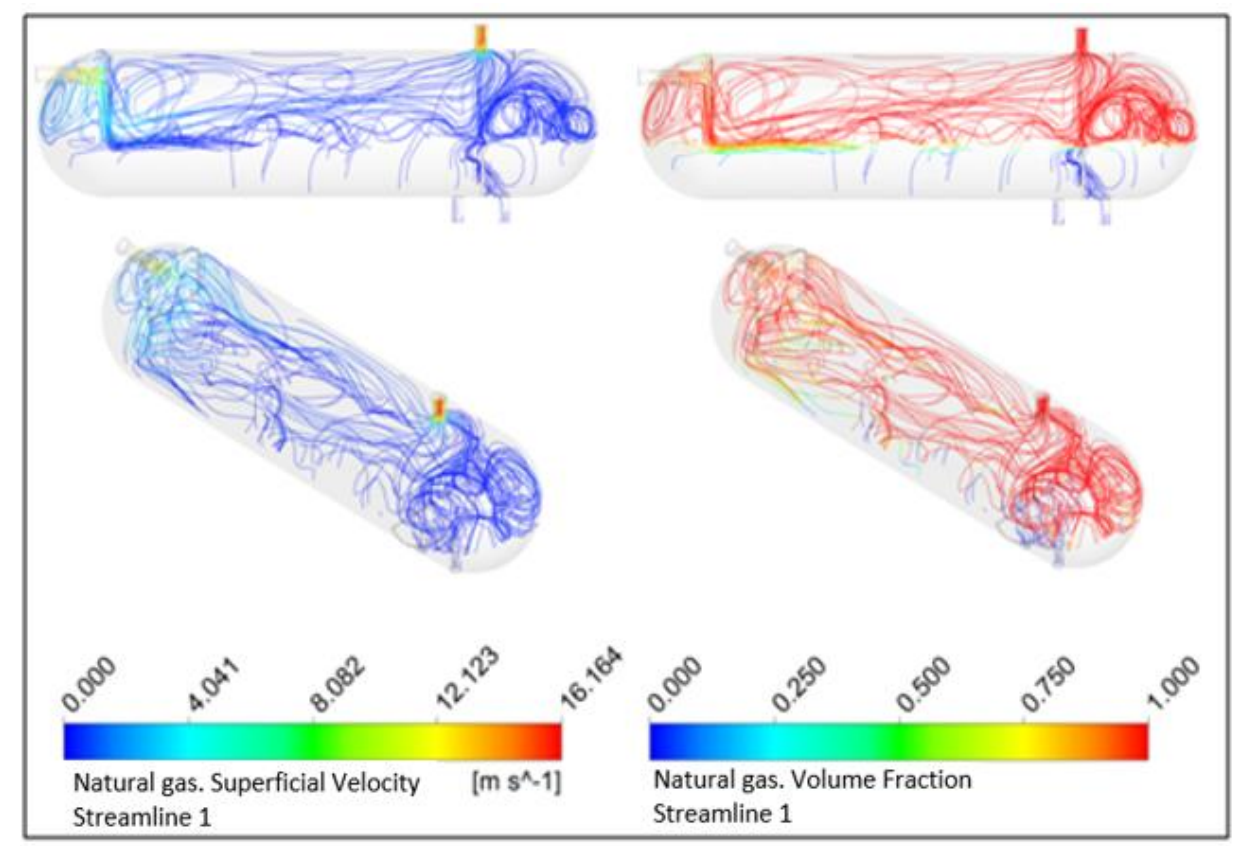

Figure 18. Gas phase streamlines (1200 s).

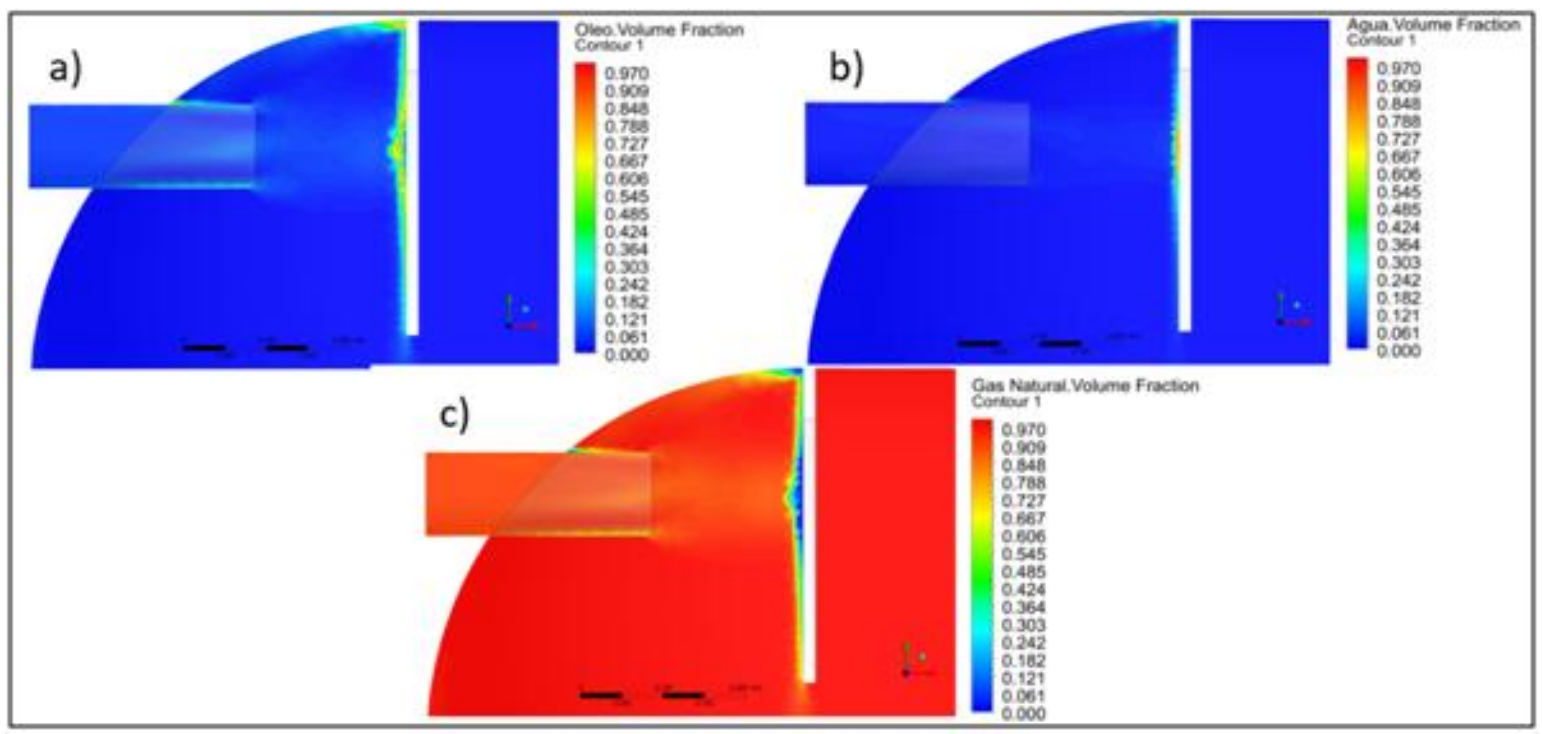

Figure 19. Volumetric fractions of a) oil, b) water, and c) gas in the deflector plate.

Figure 18 shows the streamlines for the gas phase, focusing on surface speed and volumetric fraction. As in the case of the other two fluids, the natural gas presents a sharp drop in velocity after the shock with the inlet diverter. After the impact, the gas presents several turbulence points, mainly at the ends of the vessel, generating circular movements. The lightness of the gas partially limits it from invading the region of liquids, despite the great gas/liquid ratio at the entrance of the equipment. Since the separation between gas and liquid happens quickly, this pattern of gas streams can be observed for almost all simulation time, even before the process has stabilized. This has prevented liquids from being dragged through the gas, so that a flow with $100 \%$ gas at the gas outlet is obtained practically in all time steps. 


\subsection{Inlet diverter effect analysis}

The inertial separation caused by the collision between fluid flow and inlet diverter is one of the main mechanisms for phase separation in a separator vessel. Figure 19 gives the volumetric fraction of oil, water, and gas in the shock region, showing the separation between the three components. While at the inlet it is possible to see a predominance of gas, since it represents $92 \%$ of the fluid flows, near the diverter there is a greater presence of the liquid components, with the heaviest phase (water) in the center, leaning against the diverter and the intermediate phase (oil) around it. The separation happens almost instantaneously.

Besides phase separation, the inlet diverter affects the fluids' speed and trajectory. Figure 20 shows the streamlines of the three components. By looking at the figure, it is possible to observe the difference between the paths of liquid and gas. Oil and water have a very sharp drop in velocity, and a tendency to go down to the lower part of the separator. Gas, on the other hand, after the impact, tends to stay in the higher parts due to its low density, when compared to liquid.

\subsection{Fluid flow variation}

In order to evaluate the influence of fluid flow at the separator inlet, two additional simulations were made. The first one was considered the inlet velocity as $15 \mathrm{~m} / \mathrm{s}$ (flow rate: $0.12161 \mathrm{~m}^{3} / \mathrm{s}$ ), and, the other one, $17 \mathrm{~m} / \mathrm{s}$ (flow rate: $0.137824 \mathrm{~m}^{3} / \mathrm{s}$ ). The results were compared with those of the Standard Case (velocity: $13 \mathrm{~m} / \mathrm{s}$; flow rate: $0.105395 \mathrm{~m}^{3} / \mathrm{s}$ ). The graph in Figure 21 shows the volumetric fraction of oil at the oil outlet during the 20 minutes of simulation.

The graph presents relatively similar behaviors between $13 \mathrm{~m} / \mathrm{s}$ and $15 \mathrm{~m} / \mathrm{s}$. The time required for the vessel to produce more than $90 \%$ oil, between $13 \mathrm{~m} / \mathrm{s}$ and $15 \mathrm{~m} / \mathrm{s}$, is only 30 seconds apart. In the $17 \mathrm{~m} / \mathrm{s}$ case, the separator stabilized before. However, as shown in Figure 22, the separation efficiency for this case starts to drop considerably after a certain time.

After 1000 seconds, the $17 \mathrm{~m} / \mathrm{s}$ case starts to lose efficiency sharply, showing greater drag of both water and gas. The presence of waves near

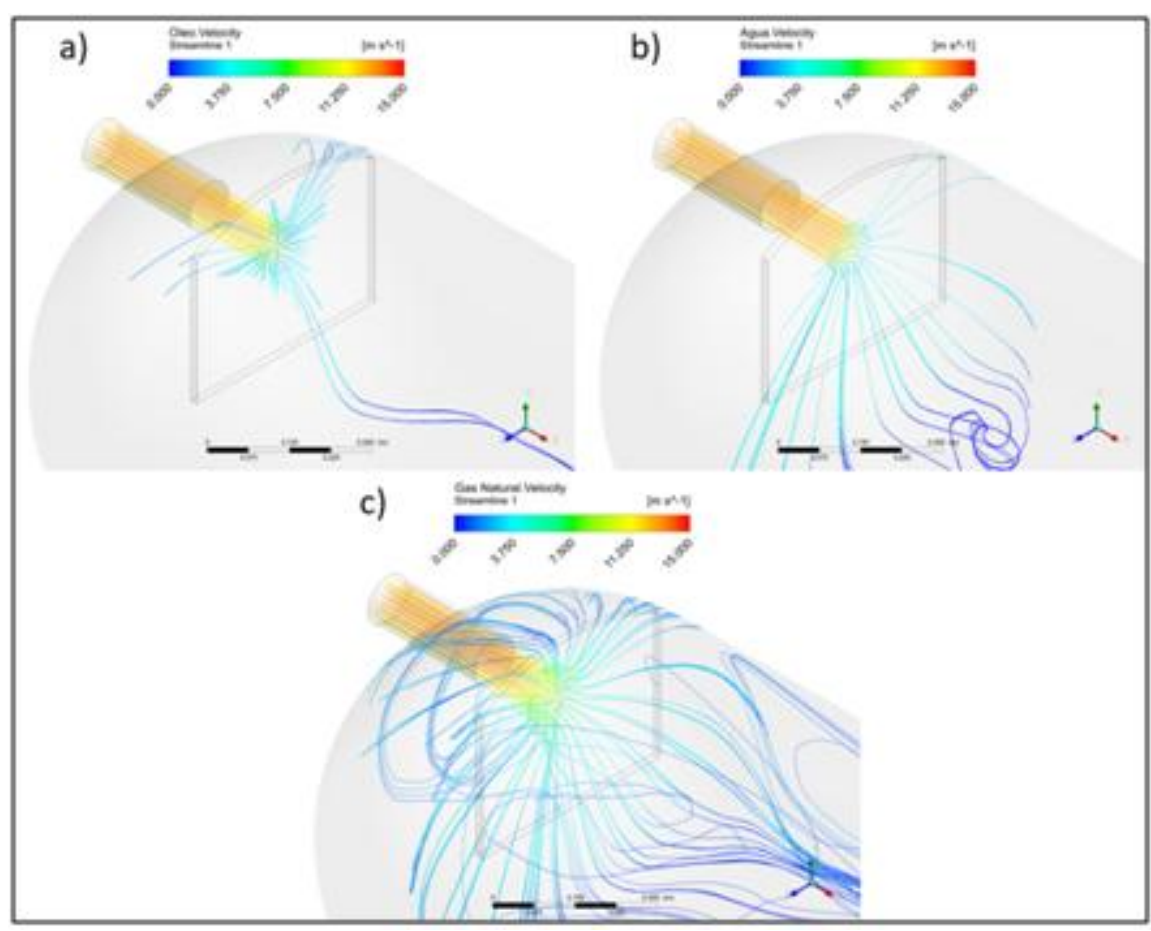

Figure 20. Streamlines of a) oil, b) water, and c) gas in the deflector plate. 


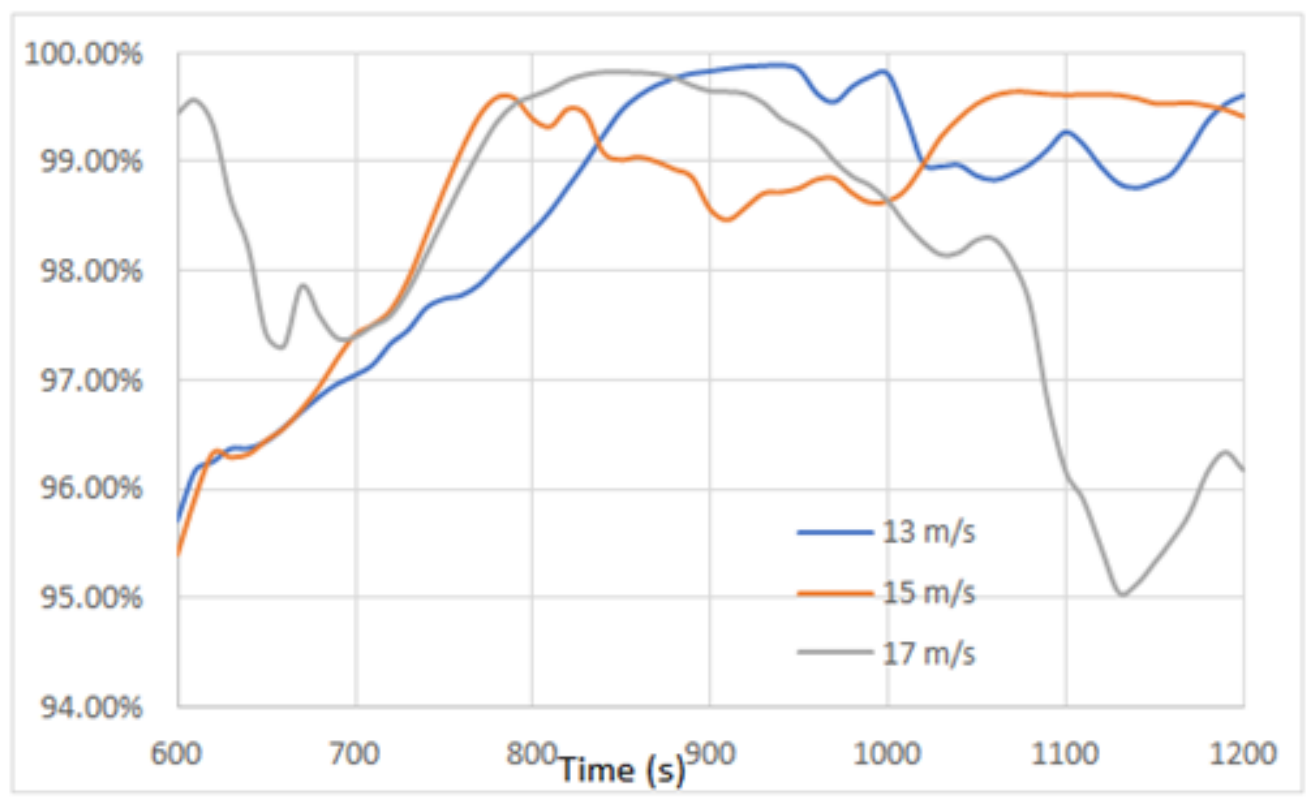

Figure 21. Oil volumetric fraction at oil outlet.

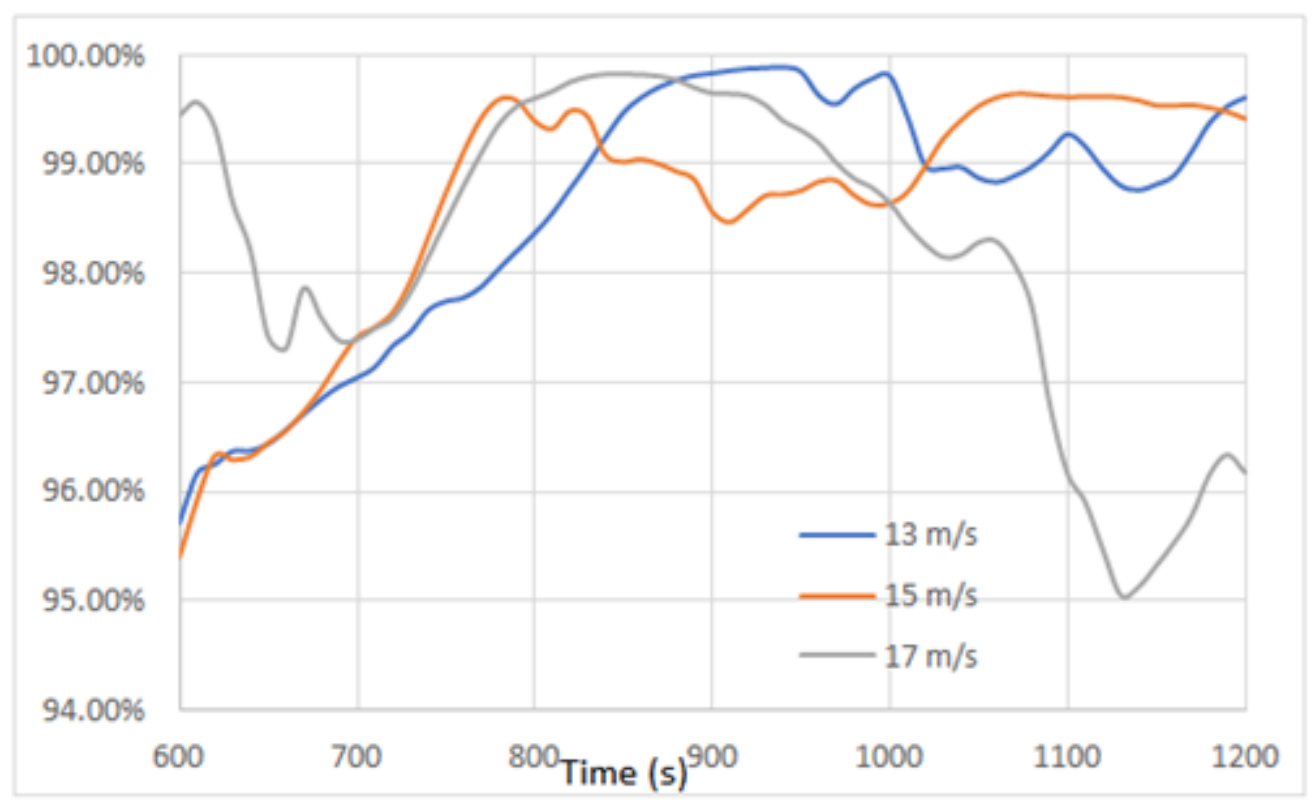

Figure 22. Oil volumetric fraction at oil outlet in the last 10 minutes of simulation.

the oil accumulation section combined with the high level of liquids allows a small amount of water to overflow, accumulating near the oil outlet. In the remaining two cases, the disturbance is not significant enough to cause problems, making the results quite similar. At the end of the simulation, the values obtained for the oil volumetric fraction at the outlet were $99.6074 \%$ for $13 \mathrm{~m} / \mathrm{s}, 99.4214 \%$ for $15 \mathrm{~m} / \mathrm{s}$, and $96.1762 \%$ for $17 \mathrm{~m} / \mathrm{s}$. For the water and gas outlets, there were no significant differences between the three cases, which showed satisfactory results (more than 99.5\% purity) during practically the entire simulation time. There are more chances of forming more turbulence points in the oil and water streams with the increase of the inlet flow, with the formation of swirls. This phenomenon can lead not only to an intensification of separation difficulty but also to the formation of waves capable of dragging portions of water to the oil accumulation section. 


\section{CONCLUSIONS}

Analyzing the results achieved through the simulations performed, we observed that the mathematical modeling proposed to describe the fluid dynamics behavior inside a horizontal threephase separating vessel was able to reproduce satisfactorily the physical phenomena present in this type of equipment. The model made it possible for us to visualize the separation between the three phases, the pressure gradient inside the vessel, the streamlines, and the effect of the inlet diverter. It is important to point that the results of the Standard Case had a very similar behavior to the ones shown by Ghaffarkhah et al. (2017) and Triwibowo et al. (2017), demonstrating the consistency of the results.

The present study shows that the increase in flow may cause loss in efficiency of the vessel. After 20 minutes of simulation, for a $17 \mathrm{~m} / \mathrm{s}$ inlet velocity, the volumetric fraction of oil at the oil outlet was $96.1762 \%$ against $99.4214 \%$ for $15 \mathrm{~m} / \mathrm{s}$, and $99.6074 \%$ for $13 \mathrm{~m} / \mathrm{s}$. Although the vessel reached $90 \%$ oil production faster for a velocity of $17 \mathrm{~m} / \mathrm{s}$, it lost its efficiency sharply after 1000 seconds of simulation, showing great drag of water and gas. This result happened because of the disturbances caused by the waves near the oil accumulation section, as well as the high liquid volume, which allows a small amount of water to overflow and accumulate near the oil outlet. None of the cases studied presented problems related to liquid drag at the gas outlet, with values of approximately $100 \%$ of gas in practically all the simulation time. There were also no problems in the water outlet, it always presented a minimum presence of unwanted fluids.

The computational fluid dynamics (CFD) proved to be a powerful tool in studying fluid behavior in multiple situations. Besides allowing a better understanding of the phase separation process, this type of software can be used to perform pretests under various operating and sizing conditions, allowing a better prevention of operational problems in real situations, reducing risks of serious errors.

\section{NOMENCLATURE}

\section{Latin Letters}

$r_{\alpha} \quad$ volumetric fraction of phase $\alpha$

$\vec{U}_{\alpha} \quad$ speed of phase $\alpha$

$\mathrm{m} / \mathrm{s}$

$\mathrm{t}$ time

$\mathrm{S}$

p pressure

$A_{\alpha \beta} \quad$ specific mass of the interfacial area

$\mathrm{Pa}$

$\mathrm{m}^{-1}$

$\vec{U}_{\alpha} \quad$ speed of phase $\alpha$

$\mathrm{m} / \mathrm{s}$

$\vec{U}_{\beta} \quad$ speed of phase $\beta$

$\mathrm{m} / \mathrm{s}$

$r_{\beta} \quad$ fraction of the dispersed phase

$d_{\beta} \quad$ particle diameter of phase $\beta$

$k \quad$ turbulent kinetic energy

$\mathrm{kg} \cdot \mathrm{m}^{2} / \mathrm{s}^{2}$

$q_{s t \quad \text { gas capacity at standard conditions }}$

MMscfd

$D \quad$ vessel inside diameter

$\mathrm{ft}$

$p_{o p} \quad$ operating pressure psia

$T$ temperature

Z gas compressibility factor

K empirical factor

$q_{L} \quad$ liquid capacity

bbl/dia

$V_{L} \quad$ sedimentation volume of the liquid

bbl

$t_{r} \quad$ retention time

$\min$

\section{Greek letters:}

$\begin{array}{clc}\rho_{\alpha} & \text { specific mass of phase } \alpha & \mathrm{kg} / \mathrm{m}^{3} \\ \tau_{\alpha} & \text { tension of phase } \alpha & \mathrm{kg} / \mathrm{ms}^{2} \\ \tau_{\alpha}^{\text {turb }} & \text { turbulent tension of Reynolds in } & \mathrm{kg} / \mathrm{ms}^{2}\end{array}$
phase $\alpha$

$\rho_{\alpha \beta} \quad$ mixing specific mass

$\mathrm{kg} / \mathrm{m}^{3}$

$\varepsilon \quad$ rate of turbulent dissipation

$\mathrm{m}^{2} / \mathrm{s}^{3}$

$\mu \quad$ dynamic viscosity

N.s $/ \mathrm{m}^{2}$

$\mu_{t} \quad$ turbulent viscosity

N.s $/ \mathrm{m}^{2}$

$\sigma_{k}, \sigma_{\varepsilon} e C_{\varepsilon}$ dimensional constants of the turbulence model k- $\varepsilon$.

$\begin{array}{lll}\rho_{L} & \begin{array}{l}\text { specific mass of liquid under } \\ \text { operating conditions }\end{array} & \mathrm{lbm} / \mathrm{ft}^{3} \\ \rho_{g} & \text { specific mass of gas under } & \mathrm{lbm} / \mathrm{ft}^{3}\end{array}$ operating conditions 
Symbols:

$\begin{array}{ll}\nabla . & \text { divergence operator } \\ \nabla & \text { gradient operator } \\ \otimes & \text { tensor product }\end{array}$

\section{REFERENCES}

Ahmed, T.; Russell, P. A.; Hamad, F.; Gooneratne, S. Experimental analysis and computational-fluid-dynamics modeling of pilotscale three-phase separators. SPE Production \& Operations, v. 34(4), SPE-197047-PA, 2019. https://doi.org/10.2118/197047-PA

Andrade, M. F. Dimensionamento de vasos separadores de petróleo. $42 \mathrm{f}$. Trabalho de Conclusão de Curso (Graduação em Engenharia de Petróleo) - Departamento de Engenharia de Petróleo, Universidade Federal do Rio Grande do Norte, Natal, 2014. (in Portuguese)

Anjos, R. C. N. S. Dimensionamento de vaso separador bifásico horizontal. $45 \mathrm{f}$. Trabalho de Conclusão de Curso (Graudação em Engenharia de Petróleo) - Departamento de Engenharia de Petróleo, Universidade Federal do Rio Grande do Norte, Natal, 2015. (in Portuguese)

ANSYS CFX Release 15.0. ANSYS CFX Introduction. SAS IP, Inc., 2013.

COPERGÁS. Sobre o Gás Natural. Avaible in: http://www.copergas.com.br/index.php/produtos/. Acessed in: 18 de ago. 2017. (in Portuguese)

Diniz, N. J. B. Modelagem e simulação de um vaso separador bifásico horizontal: estudo de caso. 57 f. Trabalho de Conclusão de Curso (Graduação em Engenharia de Petróleo) Departamento de Engenharia de Petróleo, Universidade Federal de Alagoas, Maceió, 2017. (in Portuguese)

Ghaffarkhah, A.; Shahrabi, M. A.; Moraveji, M. K.; Eslami, H. Application of CFD for designing conventional three phase oilfield separator. Egyptian Journal of Petroleum, v. 26(2), p. 413420, 2017. https://doi.org/10.1016/j.ejpe.2016.06.003
Kharoua, N.; Khezzar, L.; Saadawi, H. N. H. Using CFD to model the performance of retrofit production separators in Abu Dhabi. Abu Dhabi International Exhibition \& Conference, Society of Petroleum Engineers, SPE-161521-MS, Abu Dhabi, 11-14 November 2012.

https://doi.org/10.2118/161521-MS

Kunert, R. (Ed.) Processamento primário de petróleo. Rio de Janeiro: Universidade Petrobras Escola de Ciências e Tecnologia E\&P, 2007.

Mariano, J. B. Impactos ambientais do refino de petróleo. 289 f. Dissertação (Mestrado em Ciências em Planejamento Energético) - COPPE, Universidade Federal do Rio de Janeiro, Rio de Janeiro, 2001. (in Portuguese)

Nakayama, Y. Introduction to Fluid Mechanics. $1^{\text {st }}$ Ed. Oxford: Reed Educational and Professional Publishing Ltd, 1999. https://doi.org/10.1016/B978-008-102437-9.00001-2

Scapin, N.; Cadei, L.; Montini, M.; Montenegro, G.; Bianco, A.; Masi, S. An Eulerian-Eulerian approach for oil \& gas separator design. In: Offshore Mediterranean Conference and Exhibition, OMC-2017-670, Ravenna, Italy, 29-31 March 2017.

Silva, L. D. S., Marinho, J. L. G. Study on Pressure Drop and Liquid Volume Fraction of the Oil-Gas Flow in a Vertical Pipe Using CFX and the Beggs and Brill Correlation: Viscosity Effects. Brazilian Journal of Petroleum and Gas, Natal, v. 10, n. 1, p.1-8, 2016. https://doi.org/10.5419/bjpg2016-0001

Silva, R. P. Geração e caracterização reológica de emulsões de água em óleo pesado para aplicações em projetos de separadores gravitacionais. Dissertação (Mestrado em Ciências e Engenharia de Petróleo) - Instituto de Geociências, Universidade Estadual de Campinas, Campinas, 2004. (in Portuguese)

Triwibowo, B.; Prasetiawan, H.; Hisyam, A.; Fauzan, M. F., Rizky, M. H. Modeling and simulation of steady state model approach for horizontal three phase separator (HTPS). In: AIP Conference Proceedings, AIP Publishing LLC, v. 1818(1), p. 020062/1 - 020062/6), 10 Mar 2017.

https://doi.org/10.1063/1.4976926 